\title{
An Update on the Multifaceted Roles of STAT3 in the Heart
}

\author{
Zeina Harhous ${ }^{1,2,3}$, George W. Booz ${ }^{4}$, Michel Ovize ${ }^{2,3}$, Gabriel Bidaux ${ }^{2,3 *}$ and \\ Mazen Kurdi ${ }^{1 *}$
}

${ }^{1}$ Laboratory of Experimental and Clinical Pharmacology, Faculty of Sciences, Doctoral School of Sciences and Technology, Lebanese University, Beirut, Lebanon, ${ }^{2}$ Univ-Lyon, CarMeN Laboratory, INSERM 1060, INRA 1397, University Claude Bernard Lyon1, INSA Lyon, Oullins, France, ${ }^{3} \mathrm{HU}$ OPeRa, Groupement Hospitalier EST, Bron, France, ${ }^{4}$ Department of Pharmacology and Toxicology, School of Medicine, The University of Mississippi Medical Center, Jackson, MS, United States

\section{OPEN ACCESS}

Edited by:

Georges Nemer,

American University of

Beirut, Lebanon

Reviewed by:

Fadi N. Salloum,

Virginia Commonwealth University,

United States

Yang Yang,

Northwest University, China

*Correspondence:

Gabriel Bidaux

gabriel.bidaux@univ-lyon1.fr

Mazen Kurdi

mkurdi@ul.edu.lb

Specialty section:

This article was submitted to

Cardiovascular Genetics and Systems

Medicine,

a section of the journal

Frontiers in Cardiovascular Medicine

Received: 14 July 2019 Accepted: 07 October 2019

Published: 25 October 2019

Citation:

Harhous Z, Booz GW, Ovize M Bidaux G and Kurdi M (2019) An Update on the Multifaceted Roles of

STAT3 in the Heart.

Front. Cardiovasc. Med. 6:150.

doi: 10.3389/fcrm.2019.00150
Signal transducer and activator of transcription 3 (STAT3) is a signaling molecule and transcription factor that plays important protective roles in the heart. The protection mediated by STAT3 is attributed to its genomic actions as a transcription factor and other non-genomic roles targeting mitochondrial function and autophagy. As a transcription factor, STAT3 upregulates genes that are anti-oxidative, anti-apoptotic, and pro-angiogenic, but suppresses anti-inflammatory and anti-fibrotic genes. Its suppressive effects on gene expression are achieved through competing with other transcription factors or cofactors. STAT3 is also linked to the modification of mRNA expression profiles in cardiac cells by inhibiting or inducing miRNA. In addition to these genomic roles, STAT3 is suggested to function protectively in mitochondria, where it regulates ROS production, in part by regulating the activities of the electron transport chain complexes, although our recent evidence calls this role into question. Nonetheless, STAT3 is a key player known to be activated in the cardioprotective ischemic conditioning protocols. Through these varied roles, STAT3 participates in various mechanisms that contribute to cardioprotection against different heart pathologies, including myocardial infarction, hypertrophy, diabetic cardiomyopathy, and peripartum cardiomyopathy. Understanding how STAT3 is involved in the protective mechanisms against these different cardiac pathologies could lead to novel therapeutic strategies to treat them.

Keywords: STAT3, cardioprotection, cardiac pathologies, myocardial infarction, genomic functions

\section{INTRODUCTION}

Cardiovascular diseases are among the top challenges to global health, constituting a leading cause for morbidity and mortality worldwide. According to the World Health Organization (WHO), these diseases result in 17.5 million deaths globally per year (1). This alarming situation increasingly excites research in the cardiovascular field, aiming to understand the mechanisms underlying different cardiac pathologies. This represents a prerequisite for developing and setting therapeutic cardioprotective strategies. A remarkable body of evidence has shown that STAT3 plays an important role in cardioprotection, rendering it a prominent focus of interest. It participates in mechanisms that contribute to protection against myocardial infarction, fibrosis, hypertrophy, hypertension, myocarditis, diabetic cardiomyopathy, and peripartum cardiomyopathy. Several previous reviews have generally addressed STAT3 functioning at the cellular level in the heart, focusing on its signaling, activation, and post-translational modifications; other reviews have 
focused solely on a particular cardiac pathology $(1,2)$. This review presents a critical appraisal of the physiological and pathological roles of STAT3 in the heart. We focus on the involvement of STAT3 in cardiac myocyte and heart pathologies, starting from a general overview of STAT3 and addressing its activation, post-translational modifications, and different cellular pools.

\section{STAT3 OVERVIEW}

\section{Structure}

STAT3 is an $89 \mathrm{kDa}$ protein encoded by the STAT3 gene. It is 770 amino acids in length and is composed of six functional domains. The $\mathrm{NH}_{2}$-terminal domain participates in higher order complex formation. This is followed by the coiled-coil domain involved in protein-protein interactions with co-regulators and transcription factors. Next is the DNA binding domain with a sequence specificity for an interferon gamma (INF $\gamma$ ) activated sequence (GAS) present in the promoter region of specific genes. Following that is the linker domain located directly before the Src homology-2 (SH2) domain, which mediates receptor recruitment and STAT3 dimerization via intermolecular phosphorylated tyrosine-SH2 interactions. The transcription activation domain (TAD), located in the $\mathrm{COOH}$-terminal region, is where regulatory phosphorylation occurs (3-5).

STAT3 exists as two main isoforms, STAT3 $\alpha$ (generally referred to as STAT3) and STAT3 $\beta$. Compared to STAT3 $\alpha$, STAT3 $\beta$ is the truncated form lacking the 55-residue Cterminal transactivation domain. This splice variant can be phosphorylated at the tyrosine 705 (Y705) residue, but unlike STAT3 $\alpha$ lacks serine 727 (S727). STAT3 $\beta$ can still bind to DNA as a homo- or heterodimer (with STAT $3 \alpha$ or other transcription factors) $(3,6)$. The role of STAT3 $\beta$ in the heart is unclear.

The main function of STAT3 is the regulation of gene transcription. STAT3 is modified at specific residues by a number of post-translational modifications with functional consequences, mainly acetylation and phosphorylation. In addition, methylation, ubiquitination, s-nitrosylation, and glutathionylation occur (5). In addition, recent evidence was reported that S-palmitoylation of STAT3 promotes its dimerization and transcriptional activation (7).

\section{Post-translational Modifications Phosphorylation \\ Tyrosine phosphorylation}

STAT3 is activated through phosphorylation of its tyrosine 705 residue (Y705) by receptor and non-receptor tyrosine kinases. This activation facilitates STAT3's homo/hetero-dimerization and DNA binding $(5,6)$. Tyrosine phosphorylation occurs in response to the stimulation by a variety of cytokines, such as IL-6, interferon gamma (IFN $\gamma$ ), and erythropoietin, in addition to growth factors such as epidermal growth factor (EGF) and fibroblast growth factor (FGF) (8-12). Tyrosine phosphorylated STAT3 molecules form dimers that translocate from the cytoplasm to the nucleus and bind to DNA. As a result, STAT3 regulates expression of genes that control cell proliferation, differentiation, and apoptosis.
In cardiomyocytes, agonists with pathophysiological importance engage membrane receptors coupled to the activation of JAK1 and JAK2 tyrosine kinases, and consequently lead to STAT3 tyrosine phosphorylation. These agonists include, in addition to IL-6 and leukemia inhibitory factor (LIF), tumor necrosis factor alpha $(\mathrm{TNF} \alpha), \mathrm{IFN} \gamma$, erythropoietin, and granulocyte-colony stimulating factor (G-CSF). The Src family kinases and bone marrow kinase on chromosome X (BMX) also induce tyrosine phosphorylation of STAT3 in cardiac cells (5).

\section{Serine phosphorylation}

Serine/threonine kinases have been shown to phosphorylate STAT3 on S727 in the cytoplasm or nucleus. The involvement of serine phosphorylation in STAT3 activities was first reported in 1995 by Zhang et al. who studied the importance of such phosphorylation for DNA binding (13). S727 was later demonstrated through mutational studies to be required for maximal transcriptional activity, but not for DNA binding $(14,15)$. Serine phosphorylation may boost the transcriptional activity of STAT3 by recruiting transcriptional co-factors, such as histone acetyltransferase p300/CBP $(13,16)$. However, there are reports as well that it may act to decrease tyrosine phosphorylation $(17,18)$.

Multiple kinases are responsible for S727 phosphorylation, depending on the nature of the activating signal. Mitogen activated protein kinase (MAPK) family members are mainly reported to induce this phosphorylation in response to different extracellular stimuli. The MAPK family is composed of extracellular signal-regulated kinase (ERK), induced by growth factors and cytokines, as well as JNK/stress-activated protein kinase and p38/HOG1 (p38 MAPK), both activated by proinflammatory cytokines and environmental stresses $(19,20)$. Among them, the best characterized serine kinases inducing S727 phosphorylation are ERK1/2. It is important to note that JNK and $\mathrm{p} 38$ are considered mediators of ischemia-reperfusion injury, where they upregulate inflammatory cytokines and activate mitochondria-dependent death pathways (21). JNK and p38 MAPKs are activated by TNF $\alpha$, which is activated during cardiac conditioning (22). During heart failure, the expression of the heat shock protein $\mathrm{H} 11$ kinase/Hsp22 increases as a stress-response mechanism. This was shown to increase the phosphorylation of STAT3 on S727, along with an increase of mitochondrial respiration ensuring cardioprotection (23).

\section{Acetylation}

Besides phosphorylation, the function of STAT3 is also regulated by p300-mediated acetylation of lysine residues within its $\mathrm{NH} 2$ terminus (K49, K87) and SH2 (K685) domains. Acetylation of K49 and K87 was shown to be important for transcription through strengthening or enhancing the interaction of STAT3 with the histone acetyltransferase p300, which stabilizes the enhanceosome assembly and ensures retention of STAT3 in the nucleus $(24,25)$. In addition, by recruiting p300, STAT3 positively affects the accessibility of other transcription factors to some promoters. K685 acetylation is important for STAT3 dimer formation and transcription enhancement at certain genes, perhaps independent of tyrosine phosphorylation $(16,26,27)$. 
In addition, evidence was reported that increased p300 acetyl transferase activity in neonatal rat ventricular myocytes positively affected STAT3 activation and half-life (28).

\section{S-Nitrosylation}

It has become clear that nitric oxide (NO) is an endogenous regulator in cardiovascular physiology and cellular respiration. The presence of NO provokes S-nitrosylation, a ubiquitous post-translational modification, by selective addition of nitric oxide (NO) to specific cysteine residue(s) of proteins forming S-nitrosothiol (SNO). This redox-related post-translational modification can inhibit STAT3 activation. STAT3 was observed to be S-nitrosylated on C259, which inhibited JAK2-mediated Y705 phosphorylation. For instance, endogenous NO from iNOS or treatment with s-nitrosoglutathione inhibited STAT3-induced gene expression and proliferation in microglial cells. It has not been reported yet if STAT3 is s-nitrosylated in the heart under conditions where iNOS is upregulated, such as the ischemic and failing myocardium (29-31).

\section{S-Sulfhydration}

$S$-sulfhydration is a post-translational modification involved in many physiological and pathological processes. S-sulfhydration yields hydropersulfide $(-\mathrm{SSH})$ in the active cysteine residue of a protein, which mediates most of the cellular functions induced by hydrogen sulfide $\left(\mathrm{H}_{2} \mathrm{~S}\right)$. Some preclinical studies have reported that the administration of hydrogen sulfide $\left(\mathrm{H}_{2} \mathrm{~S}\right)$ decreases myocardial injury, protects blood vessels, limits inflammation and regulates blood pressure. In the context of STAT3, Wu et al. reported that $S$-propargyl-cysteine (SPRC), a producing agent of endogenous hydrogen sulfide $\left(\mathrm{H}_{2} \mathrm{~S}\right)$, possesses cardioprotective efficacy through the activation of STAT3 phosphorylation downstream of gp130. In another study, Xin et al. reported that $\mathrm{H}_{2} \mathrm{~S}$ ameliorated IL-6-induced STAT3 acetylation, which was accompanied by a decreased inflammatory response in patients with anemia. Although the presence of $\mathrm{H}_{2} \mathrm{~S}$ provokes sulfhydration, it seems that there is no direct sulfhydration of STAT3 reported in the presence of $\mathrm{H}_{2} \mathrm{~S}$, but rather the presence $\mathrm{H}_{2} \mathrm{~S}$ induces phosphorylation or acetylation (31-34).

\section{STAT3 POOLS AND TRANSLOCATION \\ Nuclear STAT3}

STAT3 is predominately cytoplasmic in resting cells, but its role as a DNA-binding transcription factor naturally depends on its ability to gain entrance to the nucleus. This facilitates its ability to transduce signals from the receptor to the appropriate target genes in the nucleus $(35,36)$. At the genomic level, STAT3 positively regulates the expression of anti-apoptotic (Bcl-2 and Bcl-xl) (6) and anti-oxidative (MnSOD and Metallothionein MT1/MT2) proteins (37). It reduces the expression of the proapoptotic factor $\mathrm{BAD}$ and regulates expression of some growth factors, such as vascular endothelial growth factor (VEGF) (38). The deletion of STAT3 in cardiac myocytes eliminated the upregulation of the anti-apoptotic (Mcl-1, Bcl-xL, c-FLIP) and cardioprotective (COX-2 and $\mathrm{HO}-1$ ) proteins, which reflects the cardioprotective roles of STAT3 as a transcription factor (39).

\section{Mitochondrial STAT3}

Although it was originally assumed that STAT3-dependent biological effects are due to its potency as a transcription factor capable of regulating gene expression, evidence of its mitochondrial presence and activity has emerged $(40,41)$. In this context, STAT3 has been reported to control electron transport chain (ETC) activity and adenosine $5^{\prime}$-triphosphate (ATP) production $(37,42-46)$. This activity has been suggested to be dependent on S727 phosphorylation in different types of cells including cardiomyocytes $(46,47)$. Among the approaches used for studying STAT3's mitochondrial activity are STAT3 $\mathrm{KO}$ models, pharmacologic inhibition, and the overexpression of a mitochondria-targeted STAT3 with mutated DNA-binding domain (MLS-STAT3E) $(37,46,48)$. However, these approaches may be questioned for several reasons. First, STAT3 is known to regulate genes involved in metabolism and mitochondrial activity (40), so the use of KO STAT3 models may be misleading in the context of a mitochondrial presence for STAT3. Second, the use of MLS-STAT3E is non-physiological, since it provokes forced STAT3 mitochondrial translocation and may point toward a misleading involvement for STAT3 in the regulation of mitochondrial activity. Therefore, the mitochondrial role has sparked controversy and seems unclearly defined in cardiac cells specifically. In this regard, Harhous et al. recently reported that STAT3 is not detected in mitochondria of adult cardiac myocytes from C57bl5/J mice and does not regulate mitochondrial calcium retention capacity or respiration activity (49). Similarly, another previous study performed on mouse heart mitochondria also failed to detect pS727-STAT3 in mitochondria (50). Overall, the presence of STAT3 in mitochondria of cardiac cells remains a controversial issue.

\section{ROLES OF STAT3 IN CARDIOMYOCYTE PATHOLOGIES}

\section{STAT3 in Ischemia-Reperfusion Injury}

Ischemia-reperfusion (IR) injury is a pathological state caused by an initial low supply of blood to a specific area, followed by the restoration of perfusion and reoxygenation (reperfusion). This injury is associated with a profound inflammatory response (51, 52). During ischemia, apoptotic and necrotic cell death occur. However, cell death is enhanced during reperfusion, and thus contributes mainly to IR injury $(53,54)$. A significant body of in vivo and in vitro evidence suggests that STAT3 activation results in a cardioprotective response to ischemia and IR injury.

\section{STAT3 Phosphorylation During IR Injury}

During ischemia, STAT3 is generally phosphorylated on its Y705 residue with a further increase in phosphorylation of this residue during reperfusion (1,55-61). However, phosphorylation of S727 was reported to be suppressed in the nucleus and mitochondria during reperfusion (1). The pattern of STAT3 activation has been described by Somers et al. who reported that pY705-STAT3 was increased in mitochondria, but decreased in the cytosol after a short reperfusion period (62). In the context of IR injury, Meier et al. recently revealed that oxidative stress and cytokines, which are supposedly important mediators of IR injury, dynamically 
regulated mitochondrial STAT3. Their results highlighted that $\mathrm{H}_{2} \mathrm{O}_{2}$ and different cytokines induced a rapid loss of STAT3 (within few minutes) from mitochondria, and a rapid recovery also, dependent on the phosphorylation of the S727 residue. Although this study was performed on different cell types, it was not assessed in cardiac cells (63).

\section{Upstream Activators of STAT3 During IR Injury}

A notable relationship exists between cardiac IR injury and the production of IL- 6 cytokines, which are among the most prominent activators of STAT3 $(19,60,64-66)$. These cytokines were shown to mediate cardioprotection against acute MI through JAK-STAT3 activation $(60,61)$. In addition to cytokines, angiotensin II has been linked to STAT3 activation during ischemia. In this regard, Omura et al. reported that angiotensin II mediated the activation of myocardial JAK-STAT3 in acute myocardial ischemia in an in vivo study with Wistar rats (59). Moreover, insulin was shown to induce cardioprotection against IR injury through activation of the JAK-STAT3 pathway (61). A number of other factors have been demonstrated to activate STAT3 in the context of IR injury with a protective effect observed, including TNF- $\alpha$, sphingosine-1-phosphate, HDL, ethanolamine, and melatonin (1).

\section{Mechanisms Contributing to the Protection Against IR Injury}

Activated STAT3 contributes to protection against IR injury through decreasing ROS generation and apoptosis, delaying MPTP opening, and increasing angiogenesis.

STAT3 upregulates anti-apoptotic proteins. Knockout of STAT3 induced a significant increase in infarct size associated with enhanced apoptosis of cardiomyocytes following IR $(1,57)$. Using a cardiomyocyte-specific STAT3 KO model, Bolli et al. reported that STAT3 deletion eliminated delayed preconditioning-induced upregulation of anti-apoptotic (Bcl-xL, c-FLIPL, Mcl-1, and c-FLIPS) and cardioprotective (HO-1 and COX-2) proteins (39). Using a similar model, Enomoto et al. reported that STAT3 expression in cardiac myocytes contributes to remodeling during the subacute phase of MI (67). Moreover, inhibition of the JAK/STAT pathway by AG490 significantly inhibited STAT3 phosphorylation in rat hearts and increased caspase- 3 activity and Bax expression in viable myocardium following infarction (56).

Concerning ROS regulation, STAT3 is capable of decreasing ROS in cardiomyocytes indirectly through upregulating the expression of antioxidants and (purportedly) directly by decreasing ROS generation in mitochondria. On the one hand, STAT3 upregulates expression of ROS scavengers and antioxidants: metallothioneins and MnSOD $(68,69)$. On the other hand, STAT3 decreases ROS generation by complexes I and III of the ETC. Boengler et al. reported that the STAT3 inhibitor Stattic decreased ADP-stimulated mitochondrial respiration and enhanced calcium-induced opening of the mitochondrial permeability transition pore (MPTP) as a result of ROS generation (70), although others reported contrary findings (49). In addition to these roles, other cardioprotective roles of STAT3 have been ascribed to the involvement of STAT3 in the upregulation of pro-angiogenic genes (VEGF and VE-cadherin) (71) and in suppression of miRNA199a transcription (72).

\section{STAT3 in MI-Induced Fibrosis and Hypertrophy}

In the context of MI-induced fibrosis and hypertrophy, cardiomyocyte-specific ablation of STAT3 exacerbated cardiac fibrosis during the subacute phase of MI, along with an increase in the expression of fibrosis-related genes, most probably due to increased death of cardiomyocytes. Besides, cardiac hypertrophy was enhanced by STAT3 ablation after MI in mouse hearts and consequently, capillary density was perhaps reduced in the border zone (67).

\section{STAT3 in Pre- and Post-conditioning}

Two main signaling pathways have been identified as contributors to the infarct-reducing effect of ischemic preconditioning (73). The first is the Reperfusion Injury Salvage Kinase (RISK) pathway, which involves activation of extracellular regulated kinases ERK1/2 and Akt. The second is the Survivor Activator Factor Enhancement (SAFE) pathway, which involves activation of the JAKSTAT3 signaling cascade. Thus, as a key player of the SAFE pathway, STAT3 mediates cardioprotective effects of ischemic conditioning (74).

The involvement of STAT3 in the cardioprotective effects of conditioning was proved using different animal models, including mice, rats, rabbits, and pigs. It was shown through knocking out STAT3, inhibiting STAT3 with stattic, or inhibiting the JAK-STAT pathway with AG490. Although few studies focused on S727 STAT3 phosphorylation during conditioning, the primary targeted phosphorylation residue is Y705. Starting with the mouse models, Xuan et al. reported that JAK1/2 phosphorylation was increased within 5 min of preconditioning, while Y705 phosphorylation of STAT3 significantly increased within $30 \mathrm{~min}$. Phosphorylation and cardioprotection were blocked by AG490 (75). In addition, cardiomyocyte-specific deletion of STAT3 abolished the cardioprotective effect of both ischemic and pharmacological preconditioning induced by adenosine, diazoxide, and TNF (76). Using the same animal model, it was reported that STAT3 is essential for the cardioprotective effect of ischemic post-conditioning induced by 3 cycles of IR ( $10 \mathrm{~s}$ ischemia- $10 \mathrm{~s}$ reperfusion). This protocol was shown to induce serine phosphorylation of STAT3 within $10 \mathrm{~min}$ of reperfusion. The use of AG490, however, abolished cardioprotection and STAT3 phosphorylation. Surprisingly, modification of the ischemic post-conditioning protocol to 5 cycles of $5 \mathrm{~s}$ ischemia- $5 \mathrm{~s}$ reperfusion showed normal cardioprotection regardless of cardiomyocyte-specific STAT3 deletion. This indicates that cardioprotection by ischemic post-conditioning is dependent on the choice of the post-conditioning protocol, where the number of cycles and duration of ischemia/reperfusion per cycle are a consideration (77).

In rabbit models as well, post-conditioning was shown to induce cardioprotection through the phosphorylation and activation of both JAK and STAT3 proteins, an effect abolished by AG490 (78). In rat models, ischemic preconditioning prior 
to $30 \mathrm{~min}$ of global ischemia and $2 \mathrm{~h}$ of reperfusion induced extensive phosphorylation of JAK2 and STAT3 in the preconditioned hearts, which was almost completely abolished by an inhibitor of JAK2, AG490 (79). This highlights the importance of JAK2/STAT3 pathway in the cardioprotective effects of pre-conditioning. In the same context, STAT3 has been reported to contribute to the cardioprotective effects of postconditioning by stimulating respiration and inhibiting MPTP opening (48).

In addition to the in vivo animal models, some groups used in vitro cellular models of cardiomyocytes and cardiomyoblasts. For instance, Suleman et al. (80) used models of ischemic and pharmacological (i.e., with TNF) preconditioning on WT and STAT3-KO mice-isolated adult mouse cardiomyocytes. Both preconditioning stimuli failed to protect KO cardiomyocytes, and the addition of AG490 abolished preconditioning in WT cardiomyocytes. In a study on $\mathrm{H} 9 \mathrm{c} 2$ cells, another team reported that pharmacological post-conditioning with S1P involves JAK-STAT3 activation. The use of AG490 or Stattic abolished the protective effect of S1P, again pointing out the necessity of this pathway in achieving the protective effect (81).

Although a good amount of work on the JAK-STAT3 pathway shows its involvement, solely, in the protective effects of preand post-conditioning, some articles have raised a question concerning its role in the RISK pathway. In this context, Goodman et al. claimed that JAK-STAT signaling is insufficient for effective post-conditioning without PI3K-Akt activation in C57bl male mice (82). However, this interlink was not thoroughly investigated. Bearing in mind that SAFE and RISK pathways have common downstream endpoints, and cellular signaling pathways are complexly entangled, the interplay between SAFE and RISK represents an important field of interest for further investigation.

\section{Mechanisms of STAT3 Involvement in Ischemic Conditioning}

STAT3 participates in conditioning-induced cardioprotection by reducing apoptosis, increasing expression of cardioprotective proteins, protecting mitochondrial respiration, and delaying mPTP opening.

\section{Apoptosis \\ Post-conditioning significantly increases anti-apoptotic Bcl2 expression, along with STAT3 phosphorylation during early and prolonged reperfusion. The use of the JAK inhibitor AG490 abolishes both effects and increases apoptosis, indicating a role of JAK-STAT3 signaling in apoptosis reduction by ischemic post-conditioning $(78,83)$. In addition, STAT3 was recently reported to be involved in the cardioprotective anti-apoptotic effects of sevoflurane-induced pharmacological post-conditioning (84). Moreover, STAT3 deletion abolished upregulation of anti-apoptotic genes such as induced myeloid leukemia cell differentiation protein (MCl-1), B- cell lymphoma-extra-large protein (Bcl-XL), and cellular FLICE inhibitory protein (c-FLIP) in response to delayed preconditioning (39).}

\section{Cardioprotective protein upregulation}

STAT3 deletion or AG490 administration abolished the upregulation of cardioprotective (COX-2 and HO-1) proteins that were normally expressed in response to delayed preconditioning $(39,85)$.

\section{Mitochondrial STAT3 and ischemic conditioning}

Heusch et al. studied mitochondrial STAT3 activation by ischemic post-conditioning. Although previous reports highlighted the role of the S727 residue in translocation of STAT3 to mitochondria, this group reported, using an in situ pig model, that ischemic post-conditioning induced an increase in Y705 phosphorylation of STAT3 in the mitochondrial compartment. This was accompanied by protection of mitochondrial respiration and an increase in the calcium retention capacity. Again, AG490 and stattic abolished postconditioning-induced protection of calcium retention capacity and respiration (44).

In conclusion, STAT3 stands out as an important participant in different types of conditioning protocols. Various studies have reported its phosphorylation and activation following different durations of early reperfusion after conditioning, going up to $120 \mathrm{~min}$. However, no study has determined the kinetics of variation of STAT3 phosphorylation at both, its serine and tyrosine residues, with prolonged durations of reperfusion. Further work focusing on STAT3 kinetics and the interaction with other signaling cascades and kinases would be of insightful.

\section{STAT3 in Autophagy}

Autophagy, a fundamental catabolic process, is involved in lysosomal-mediated degradation and recycling of dysfunctional and unnecessary cellular components (86). This process was shown to be linked to STAT3 in the HL-1 cell line (immortalized mouse atrial cardiomyocytes) and cardiomyocytes $(87,88)$. In HL-1 cells, STAT3 deficiency lead to increased autophagy, characterized by a significant increase in autophagolysosomes (87). In another study, alcohol was reported to increase autophagy and apoptosis by decreasing STAT3 phosphorylation (88).

The subcellular STAT3 localization pattern affects autophagy in various ways [Figure 1; (89)]. For instance, nuclear STAT3 can fine-tune autophagy through transcriptional regulation of some autophagy-regulated genes, while cytoplasmic STAT3 inhibits autophagy constitutively through sequestering the eukaryotic translation initiation factor 2 alpha kinase 2 (eif2ak2) and by interacting with other autophagy-related signaling molecules (89). Cytoplasmic STAT3 also interacts with autophagy-related proteins FoxO1 and FoxO3. The latter translocates into the nucleus and upregulates multiple autophagy-related genes. In a recent study conducted with $\mathrm{H} 9 \mathrm{c} 2$ cardiomyoblasts, Chen et al. investigated whether angiotensin II-induced cardiomyocyte hypertrophy is affected by STAT3-mediated inhibition of cellular autophagy. They reported that STAT3 modulates autophagy to balance the transcriptional hypertrophic response to angiotensin II stimulation (90). In an attempt to investigate the possible mechanism of this effect, Jonchere et al. showed that STAT3 interacts with an RNA-dependent kinase, PKR, and inhibits 


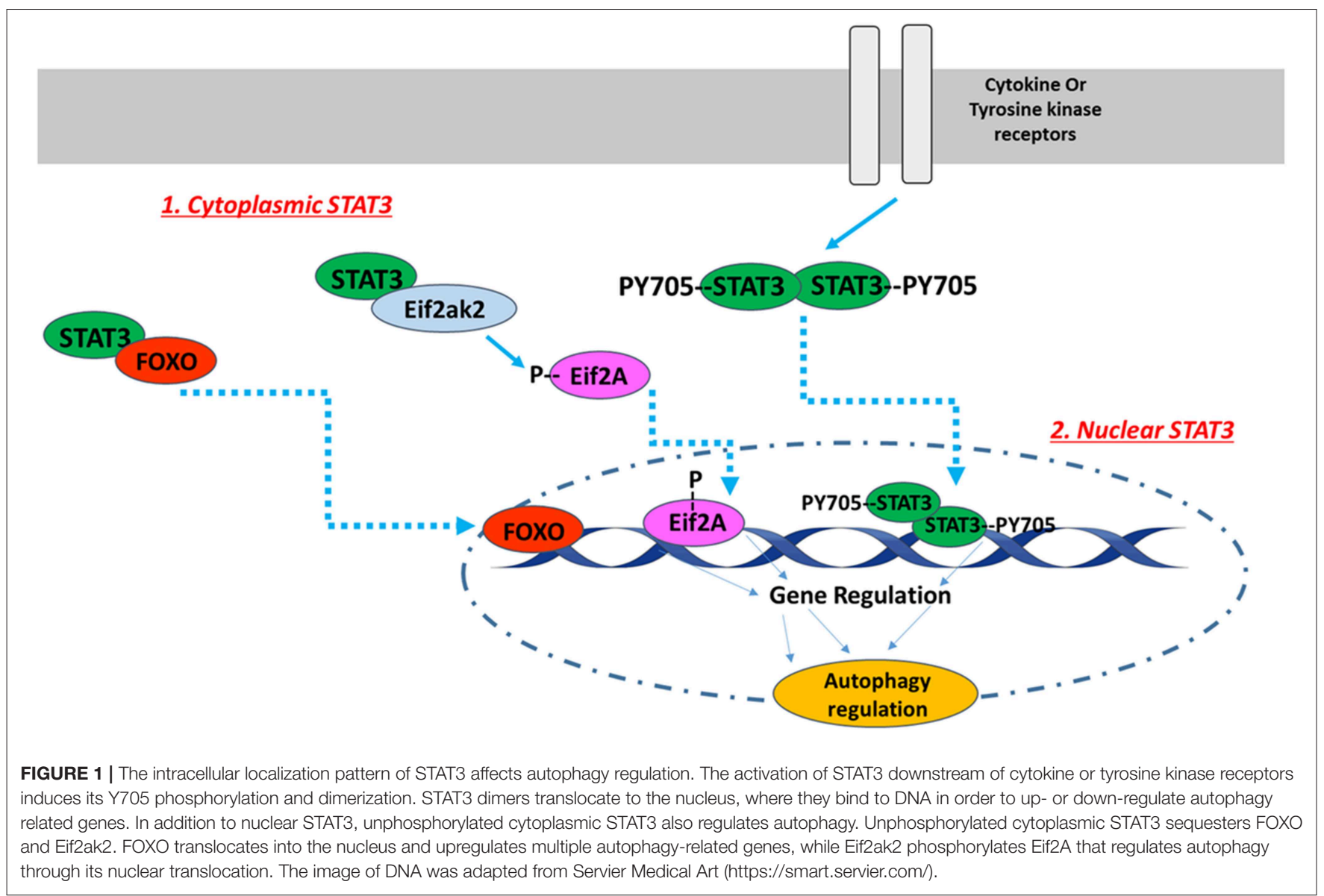

phosphorylation of eukaryotic translation-initiation factor 2alpha $(e I F 2-\alpha)$, consequently leading to the reduction of autophagy pathways (91).

Given these specified roles for STAT3 in the regulation of autophagy and noting that autophagy is among the mechanisms of cell death in IR injury (92), an important future approach will be to investigate how STAT3 regulates autophagy during IR injury or cardioprotective ischemic conditioning.

\section{STAT3 in ER Stress}

The endoplasmic reticulum (ER) plays a major role in cellular calcium homeostasis. Various stimuli such as ischemic insult, oxidative stress, and calcium disturbances lead to the accumulation of unfolded proteins, a condition named ER stress (93). Several studies have investigated involvement of STAT3 in regulating ER activity (Figure 2). However, a recent study exclusively reported unexpected STAT3 localization to the ER, from where it modulated ER-mitochondrial calcium release by directly interacting with IP3R3 and facilitating its degradation in MDA-MB-468 cells. This leads to a decrease in the calcium release from ER to mitochondria, and thus a decrease in apoptotic cell death. The S727 STAT3 residue plays a regulatory role, since a S727 mutation of STAT3 induced excessive release of calcium from ER, followed by $\mathrm{H}_{2} \mathrm{O}_{2}$-induced apoptotic cell death (94).
Since the stated mechanism cannot be generalized, its occurrence in heart/cardiomyocytes needs to be investigated.

Regarding ER stress, studies show that it is characterized by impaired activity of sarco/endoplasmic reticulum calcium ATPase (SERCA). On the other hand, well-preserved SERCA activity attenuates ER stress and protects against myocardial IR injury. In this context, using in vivo rat model of IR, the JAK2STAT3 pathway was shown to be involved in rescuing SERCA expression and activity following 3 and $24 \mathrm{~h}$ of reperfusion, and thus reducing ER stress and infarct size (95). Similarly, the naturally occurring compound berberine (BBR) protected the rat heart from IR injury through attenuating ER stress via activation of JAK2/STAT3 pathway. Inhibition of the latter blocked attenuation of ER stress by BBR (96). In addition, Banerjee et al. recently proposed that stimulation of mitochondrial STAT3FAK (focal adhesion kinase) offers a novel therapeutic approach against pathological ER stress in endothelial cells (97). In another in vitro study on $\mathrm{H} 9 \mathrm{c} 2$ cells, it was shown that the pharmacologic compound Elatoside $\mathrm{C}$ protected against hypoxia-reoxygenationinduced ER-stress by activating STAT3 signaling pathways (98).

It seems that the non-canonical activities of STAT3, which were controversially assigned to the maintenance of ETC activity in mitochondria, now include a shift toward activities at the level of ER via IP3R degradation and modulation of calcium flux. Further investigations need to be conducted on cardiomyocytes 


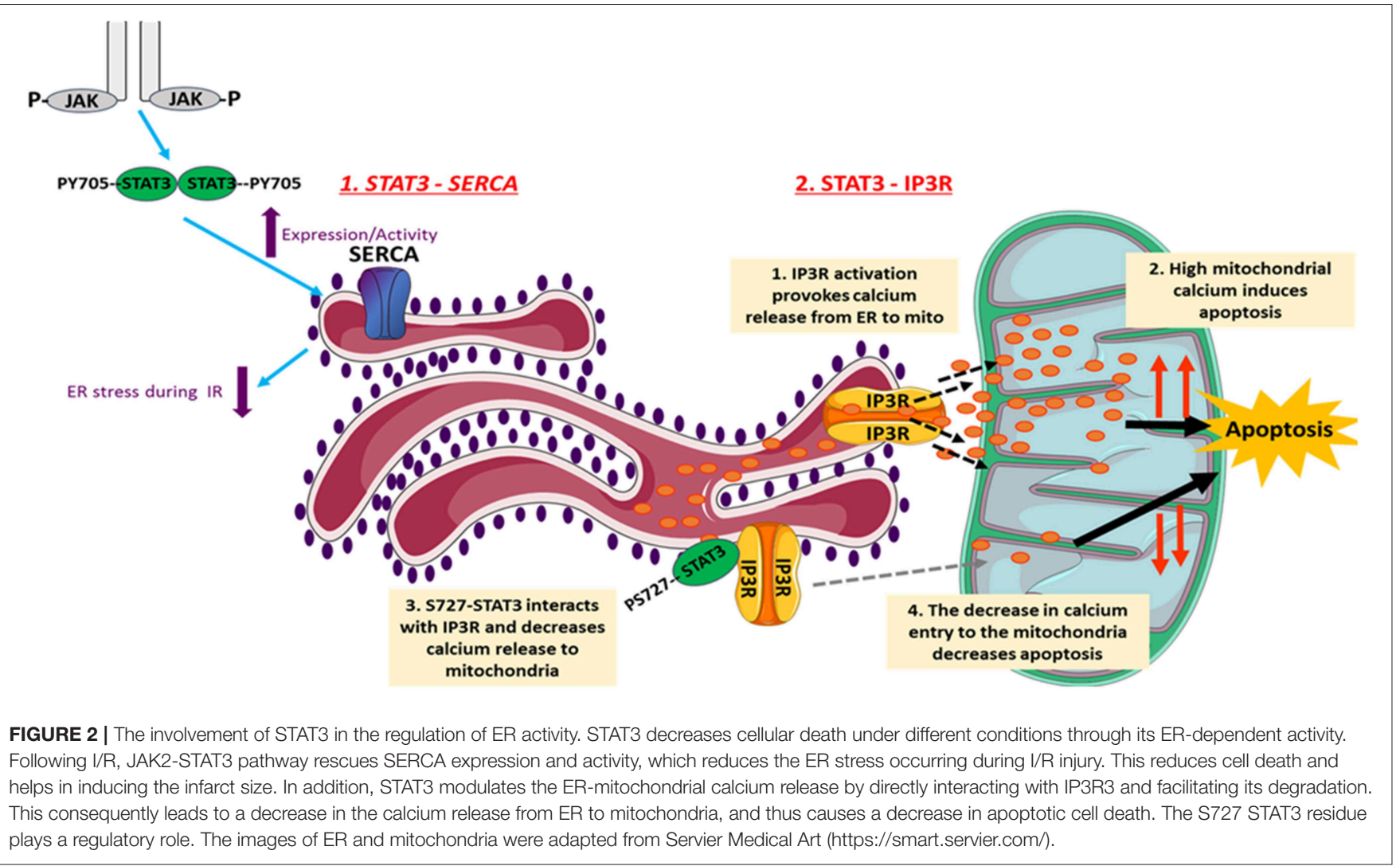

in this regard, in which it would be interesting to also assess STAT3 in the mitochondrial associated membranes (MAMs) that lie at the interface between mitochondria and ER. This might also help explain why different groups have reported different results regarding the presence of STAT3 in cardiomyocyte mitochondria.

\section{STAT3 in Cellular Metabolism}

STAT3 has been considered a potential anti-cancer target since its description as an oncogene in 1999 (41). It is implicated in the definitive metabolic abnormality which characterizes cancer cells: energy derivation using glycolysis (99). Through various activities, STAT3 plays an important role in establishing glycolysis-dependent energy derivation, via the Warburg effect [Figure 3; (100)]. The effects of STAT3 on glycolysis are mainly mediated by several connections between STAT3 and hypoxia responsive factor 1 alpha (HIF$1 \alpha)$. The oxygen sensor HIF- $1 \alpha$ is an unstable protein that becomes stabilized under conditions of hypoxia, inducing the activation of glycolysis and the down-regulation of mitochondrial respiration (101). The first connection is that STAT3 transcriptionally upregulates HIF- $1 \alpha$ mRNA and protein levels (40), along with attenuating mitochondrial activity by down-regulating mitochondrial proteins in a HIF- $1 \alpha-$ independent manner (102). Second, STAT3 is involved in a forward loop which provokes enhancement of aerobic glycolysis and proliferation (103): oxygen deprivation and oncogenes upregulate HIF-1, leading to an increase in pyruvate kinase
2 PKM2 levels. In return, HIF-1 transcriptional activity is enhanced further, and STAT3 is directly phosphorylated by PKM2. STAT3 consequently upregulates HIF-1 expression, which completes the loop (102, 104-108). In a study on MEFs expressing constitutively active STAT3 (STAT3C/C), STAT3C/C increased mRNA for a set of proteins, including PDK-l (pyruvate dehydrogenase kinase 1). This blocked the shuttling of pyruvate into the citric acid cycle in the mitochondria, sending it rather into the glycolytic pathway with resulting increased lactic acid production. Decreased mitochondrial oxidative phosphorylation was also observed in STAT3C/C cells, which was due to the fact that these cells had a lowered amount of mRNA for mitochondrial proteins (ATP synthase, $\mathrm{G}$ subunit of the mitochondrial FO complex, fumarate hydratase) (100).

Accumulating evidence indicates that preservation of bioenergetics, including maintenance of fatty acid oxidation, is important for normal cardiac function and prevention of ischemic and non-ischemic heart failure (109-111). The late stage of cardiac hypertrophy is also accompanied by impaired mitochondrial fatty acid oxidation and a shift toward a dependency on glucose metabolism, which is considered inadequate for normal cardiac function (112). To shed light on STAT3's metabolic functions, it is important to briefly reintroduce its involvement in the regulation of mitochondrial functions. As stated previously, STAT3 is known to regulate genes involved in metabolism and 
mitochondrial activity. Moreover, although its presence is not definitively confirmed in mitochondria of cardiomyocytes of all species, STAT3 is reported to regulate mitochondrial ROS production and respiration in some models. Through these roles, STAT3 is considered a key player in regulating cellular metabolic homeostasis. On the contrary, in a study that focused on the involvement of cardiomyocyte-specific STAT3 in the maintenance of cardiac energy metabolism during angiotensin II-induced hypertension, Altara et al. showed that STAT3 is not essential for the heart to maintain normal fatty acid utilization under stress conditions of cardiac hypertrophy (113).

\section{STAT3 in Microtubule Stability and Assembly}

In cardiac myocytes, microtubules (MTs) are cytoskeleton components that consist of $\alpha \beta$-tubulin heterodimers, assembled into microtubule polymers. Besides their well-established physiological roles, evidence suggests that MTs have an important role in disease conditions, such as cardiac hypertrophy and heart failure. Cooper reported that re-organization of MTs accompanied the development of cardiac disease (114), and an increase in MT numbers correlated with pressure overloadinduced pathological cardiac hypertrophy $(115,116)$. In addition, significant increases in MT number, density, and stability have been reported during heart failure (117).

STAT3 has been reported to partially co-localize with microtubules in various types of cells (118). It contributes to the dynamics and stabilization of MTs by interacting with and inhibiting the activity of stathmin (119, 120), a cytosolic protein that binds $\alpha \beta$-tubulin heterodimers and causes MT depolymerization (42). STAT3 was also reported to physically interact with tubulin, the building block of MTs (121). Nevertheless, the role of STAT3 in regulating MTs of cardiomyocytes is not well-established. In this regard, $\mathrm{Ng}$ et al. reported that the gp130 family cytokines (OSM and LIF) induced MT stabilization in neonatal rat ventricular myocytes, and this was inhibited by JAK2/STAT3 inhibitors or STAT3 knockdown (122). Paradoxically, as detected by immunofluorescence, total and tyrosine-phosphorylated STAT3 in cardiomyocytes were located in a pattern that is independent of microtubule distribution in the cells $(121,123)$. Given the physiological and pathological importance of MT stability in the heart, investigating the role of STAT3 as a regulator of this feature and its connection with physiological and pathological conditions is of great importance.

\section{ROLE OF STAT3 IN HEART PATHOLOGIES}

STAT3 participates in mechanisms contributing to different chronic cardiac pathologies including hypertension-induced hypertrophy, fibrosis, and diabetic cardiomyopathy (Table 1).

\section{STAT3 in Hypertrophy}

Cardiac hypertrophy is a compensatory response that allows the heart to cope with the pathogenic stimuli found with many cardiovascular diseases (124). Although it is a compensatory beneficial mechanism, it stands as an independent cause of death by progressing to heart failure. Among the various signaling pathways that mediate cardiac hypertrophy, the JAK/STAT pathway plays a pivotal role in response to different stimuli such as myocardial infarction, cytokines, IR, pressure overload, and neurohormones (124-128). It is activated by hypertrophic agonists [leukemia inhibitory factor (LIF), cardiotrophin-1 (CT$1)$, and angiotensin II] in vitro $(124,128,129)$. The main link between STAT3 and hypertrophy induction originated from the fact that the IL- 6 family cytokines, which activate JAK-STAT3 pathway, induce growth of cardiac cells.

Several studies highlighted involvement of STAT3 in hypertrophy through its transcriptional roles. Inhibition of STAT3 induced down-regulation of collagen synthesis and regression of hypertrophy, suggesting that STAT3 is a major potential therapeutic target for cardiac hypertrophy (130). In addition, over-expression of STAT3 in mouse cardiomyocytes caused cardiac hypertrophy by increasing expression of hypertrophic genes (ANF, MHC, CT-1) (131).

The inactivation of STAT3 resulting from the loss of gp130 may be a key event in the transition from cardiac hypertrophy to heart failure (58). In this regard, gp130 was reported to play a critical role in hypertrophy through STAT3 activation (132). It was also shown that the hypertrophic growth of neonatal rat cardiomyocytes was induced by LIF through gp130-STAT3 axis. This response was inhibited by overexpressing the suppressor of cytokine signaling negative regulator, SOCS3 (133). Although STAT3 activation has been reported downstream of JAK2 in various cardiac models of hypertrophy, it was demonstrated in an in vivo model of hypertrophy that STAT3 becomes phosphorylated with no accompanying JAK2 activation. STAT3 activation contributed to cardiomyocyte growth and survival through its transcriptional activity, and this activation was mediated through the TEC family kinase, BMX, not JAK2 (134).

On the other hand, this prominent role of STAT3 in hypertrophy was questioned by contradicting findings. In this regard, IL-6 deletion or the chronic treatment of C57bl/6J male mice with LIF did not affect development of cardiac hypertrophy $(135,136)$. In addition, it was reported that mice with cardiomyocyte-specific deletion of STAT3 developed normal pregnancy-induced hypertrophic growth of the maternal heart (137). Overall, the above findings indicate that the role of STAT3 in hypertrophy is still controversial and requires further investigation to establish STAT3-dependent signaling pathways of hypertrophy.

\section{STAT3 in Fibrosis}

Many cardiac diseases and aging are associated with fibrosis in the heart (138). The fibrotic ECM causes increased stiffness and induces pathological signaling within cardiomyocytes, which results in progressive cardiac failure. In addition, excessive ECM impairs the mechano-electrical coupling of cardiomyocytes and increases the risk of arrhythmias (139). Evidence indicates that STAT3 is an important contributor to collagen synthesis and cardiac fibrosis through its activity in fibroblasts and cardiomyocytes. 


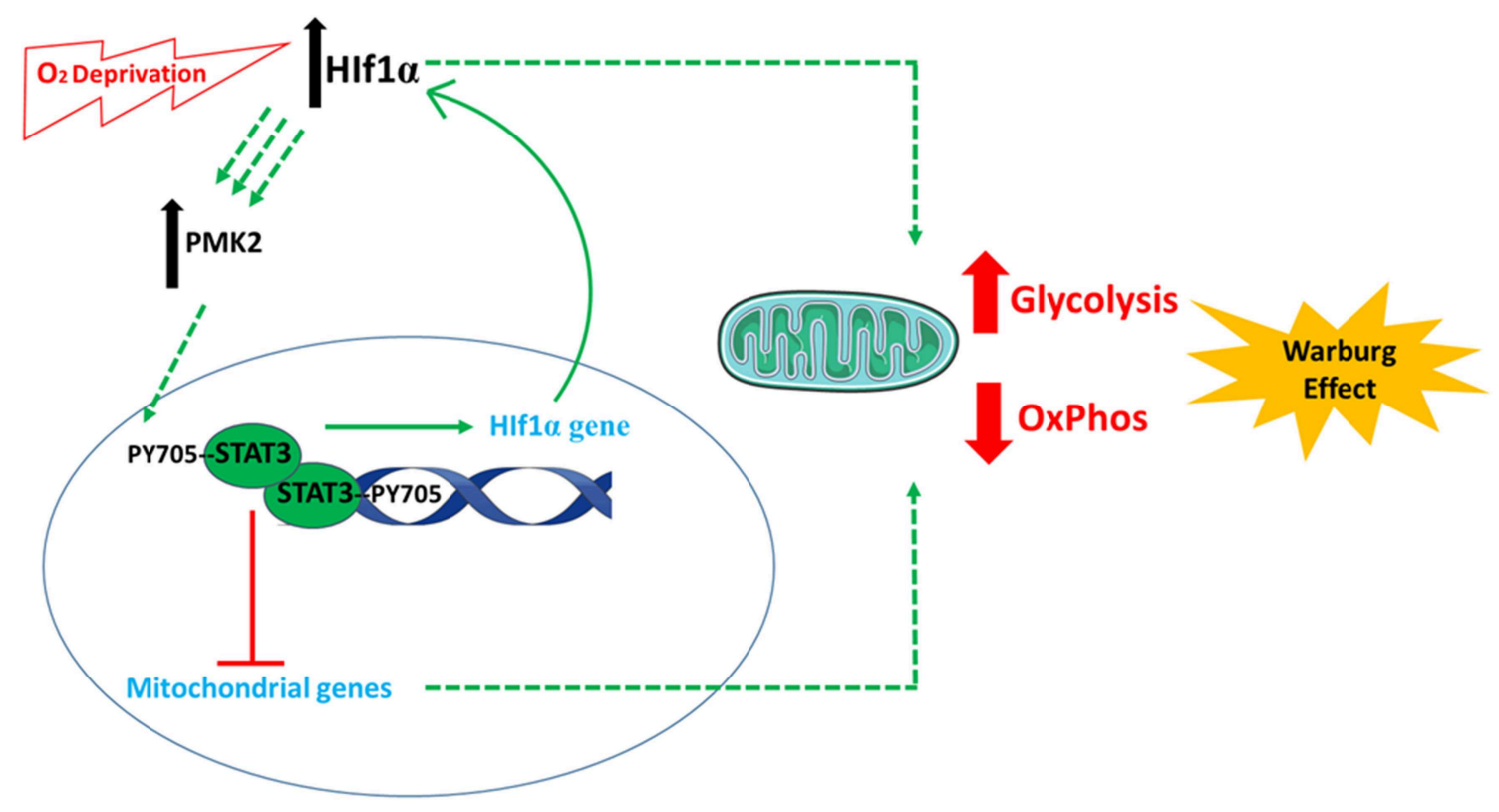

FIGURE 3 | The involvement of STAT3 in cellular metabolism. STAT3 plays an important role in establishing glycolysis-dependent energy derivation, via the Warburg effect. This is mediated by several connections between STAT3 and hypoxia responsive factor 1 alpha (HIF-1 $\alpha$ ). Following oxygen deprivation (hypoxia), the levels of $\mathrm{HIF-1} \alpha$ increase and cause an increase in pyruvate kinase 2 (PKM2) levels. PKM2 induces the phosphorylation of STAT3, which induces the expression of HIF-1 $\alpha$. In parallel, STAT3 also decreases the expression of mitochondrial genes. All these incidences finally favor anaerobic glycolysis and decrease electron transport chain activity and aerobic respiration. The images of DNA and mitochondria were adapted from Servier Medical Art (https://smart.servier.com/).

Under normal physiological conditions, activation of STAT3 is involved in the promotion of cell proliferation and survival, along with the synthesis of ECM in cardiac fibroblasts. The in vitro STAT3 activation by IL-6 induced normal production of collagen by fibroblasts (140), and the inhibition of STAT3 by S31201 induced a pronounced downregulation of collagen synthesis. In this context, Tsai et al. showed that STAT3 activation was stimulated by angiotensin II in rat atrial fibroblasts, indirectly through a paracrine effect linked to collagen synthesis and fibrosis (141). In addition to these studies, increased blood pressure due to ligation of the renal artery in the rat induced cardiac fibrosis, which was attributed to regulation of IL6 synthesis by cardiac myocytes. Consequently, STAT3 was activated in cardiac fibroblasts and enhanced the expression of collagen (142).

Studying hyperglycemia-promoted fibrosis, Dai et al. reported that STAT3 mediated the proliferation of cardiac fibroblasts and the collagen synthesis by these cells (143). In addition, evidence showed that the cell surface transmembrane ligand EphrinB2 in cardiac fibroblasts has pro-fibrotic actions via the synergistic activation of STAT3 and Smad3, which subsequently become associated (144). Moreover, another study found that the hormone relaxin inhibits TGF- $\beta 1$-induced cardiac fibrosis by blocking STAT3-dependent autophagy in cardiac fibroblasts (145).

Although the above evidence collectively shows that STAT3 is prominently involved in fibrosis, it was reported that STAT3 deletion in mouse cardiomyocytes induced development of severe fibrosis with advanced age (126). In another study on
STAT3-deficient mice, reduced myocardial capillary density was observed within the first 4 months postnatal (57). Evidence showed that STAT3 KO cardiac myocytes produce some paracrine factors that stimulate fibroblasts proliferation.

In addition to the above stated roles, STAT3 is involved in crosstalk between cardiac myocytes and fibroblasts under pathologic conditions. In cardiac cells of mouse hearts subjected to transverse aortic constriction, STAT3 was displaced from the cytoskeletal protein bIV-spectrin at intercalated discs, downstream of $\mathrm{Ca}^{2+} /$ calmodulin-dependent kinase II (CaMKII) activation. This displacement, induced by CaMKII-mediated phosphorylation of bIV-spectrin, was implicated in cardiac fibrosis and in the loss of cardiac function since it resulted in the nuclear translocation of STAT3 and induction of pro-fibrotic genes in cardiomyocytes (146).

In summary, STAT3 is important for the normal physiologic functioning of fibroblasts and for the ECM synthesis. However, its absence in cardiac myocytes induces fibrosis.

\section{STAT3 in Peripartum Cardiomyopathy (PPCM)}

Peripartum/postpartum cardiomyopathy (PPCM) is a rare heart disease that develops in women during the last month of pregnancy or within 5 months of delivery. Its typical features are apoptosis, inflammation, autoimmune processes, and impaired cardiac microvasculature (147). Observations suggest that cardiac STAT3 is optional during pregnancy, but it is necessary for cardioprotection in postpartum. 
TABLE 1 | The roles of STAT3 in various cardiac pathologies.

\begin{tabular}{|c|c|}
\hline Cardiac pathology & Roles of STAT3 \\
\hline Hypertrophy & $\begin{array}{l}\text { - STAT3-dependent hypertrophy } \\
\text { - JAK/STAT3 pathway activated by hypertrophic agonists } \\
\text { - IL-6, a main activator of STAT3, induces growth of cardiac cells } \\
\text { - Inhibition of STAT3 downregulates collagen synthesis and decreases hypertrophy } \\
\text { - Overexpression of STAT3 in CMs increases expression of hypertrophic genes } \\
\text { - STAT3-independent hypertrophy } \\
\text { - Mice with CM-specific STAT3 deletion develop normal pregnancy-induced hypertrophy } \\
\text { - IL-6 deletion or chronic LIF treatment does not affect hypertrophy }\end{array}$ \\
\hline Fibrosis & $\begin{array}{l}\text { - STAT3 in cardiomyocytes } \\
\text { - STAT3 deletion in CMs induces development of severe fibrosis } \\
\text { - STAT3 KO CMs produce paracrine factors that stimulate fibroblast proliferation } \\
\text { - STAT3 stimulates induction of pro-fibrotic genes in cardiomyocytes } \\
\text { - STAT3 in fibroblasts } \\
\text { - Activation of STAT3 by Angll stimulates collagen synthesis and fibrosis, while its inhibition induces downregulation of collagen synthesis } \\
\text { - STAT3 activation by IL-6 stimulates indirect collagen production in fibroblasts } \\
\text { - The cell surface transmembrane ligand EphrinB2 in cardiac fibroblasts has pro-fibrotic actions via synergistic activation of STAT3 } \\
\text { and Smad3 }\end{array}$ \\
\hline Peripartum cardiomyopathy & - Absence of STAT3 leads to PPCM development through oxidative stress \\
\hline Diabetes & $\begin{array}{l}\text { - Anti-diabetic roles } \\
\text { - Decrease in cardiac STAT3 phosphorylation/activation in type I diabetes } \\
\text { - S727 STAT3 phosphorylation decreases streptozotocin-induced type I diabetes } \\
\text { - Reduced expression of cardiac STAT3 reported in a type II diabetes model, where downregulation of STAT3 mRNA observed in rats } \\
\text { - High glucose induces reduction in Y705-STAT3 phosphorylation and activation in adult rat cardiomyocytes } \\
\text { - Diabetic roles } \\
\text { - Hyperglycemia shown to induce activation of STAT3 signaling pathway through JAK2 } \\
\text { - Cardiac levels of p-STAT3 increased in diabetic rats, accompanied by increase in IL-6 and collagen deposition } \\
\text { - Increased STAT3 phosphorylation observed in Wistar rats following } 21 \text {-weeks of high-fat and glucose diet } \\
\text { - STAT3 activation reported under high glucose conditions in H9C2 cells and in rat cardiac fibroblasts }\end{array}$ \\
\hline $\begin{array}{l}\text { Myocardial infarction } \\
\text { (Inflammatory approach) }\end{array}$ & $\begin{array}{l}\text { - STAT3 in cytokine signaling } \\
\text { - STAT3 is a signaling molecule downstream of pro- and anti- inflammatory cytokines: IL-6, IL-1 } \beta \text {, TNF- } \alpha \text { and IL-10 } \\
\text { - Uncontrolled STAT3 activation promotes inflammation: CM-specific mutation of gp130 receptor with uncontrolled STAT3 activation, led } \\
\text { to sustained cardiac inflammation in response to MI } \\
\text { - Accumulation of non-phosphorylated STAT3 in the nucleus induces expression of pro-inflammatory genes, including IL-6 } \\
\text { - STAT3 activation downstream of IL-10 following MI is anti-inflammatory } \\
\text { - STAT3 in neutrophil/macrophage recruitment } \\
\text { - Over activation of STAT3 results in more rapid clearance of neutrophils due to decreased production of the neutrophil-attracting chemokine } \\
\text { CXCL1 } \\
\text { - Granulocyte colony-stimulating factor (G-CSF), a key mediator of neutrophil infiltration, acts via STAT3 and other signaling pathways } \\
\text { - STAT3 demonstrated to be required for expression of Reg3b, which is secreted by cardiac myocytes to facilitate macrophage recruitment } \\
\text { - STAT3 in macrophage polarization } \\
\text { - IL-10-galectin-3 axis essential for M2 macrophage polarization after MI in STAT3-dependent manner } \\
\text { - Sodium-glucose cotransporter2 (SGLT2) inhibitors mediate M2C polarization by regulating reactive oxygen and nitrogen species } \\
\text { production through STAT3-mediated pathway } \\
\text { - STAT3-dependent pathway in post-infarcted rats regulates macrophages phenotype }\end{array}$ \\
\hline Doxorubicin cardiotoxicity & $\begin{array}{l}\text { - STAT3 overexpression in the heart protects against Dox-induced cardiomyopathy, probably through regulating expression of anti-oxidative } \\
\text { MT1 and MT2 } \\
\text { - S-propargyl-cysteine (SPRC) possesses cardioprotective efficacy against Dox by stimulating STAT3 activation via gp130-mediated } \\
\text { signaling in vitro and in vivo }\end{array}$ \\
\hline
\end{tabular}

The absence of STAT3 leads to PPCM development through oxidative stress. Female mice with cardiomyocyte-specific deletion of STAT3 develop PPCM, associated with the abrogation of superoxide dismutase 2 (MnSOD2) upregulation (137). This consequently leads to an increase in oxidative stress, accompanied by an increase in cathepsin D expression and activity. Cathepsin D provokes formation of a pro-apoptotic and anti-angiogenic cleaved $16 \mathrm{KDa}$ form of prolactin. This in turn stimulates increased miR-146a expression in endothelial cells, which release miR-146a-loaded exosomes that induce subsequent decrease in the metabolic activity of cardiac cells, accompanied by a downregulation of Erbb4, Notch1, and Irk1 expression (148, 149). Moreover, Akt activity is enhanced in PPCM downstream of prolactin, which increases the redox imbalance and SOD2 loss due to down-regulation of the anti-oxidative transcription factor FoxO3A (149).

Low levels of ventricular STAT3 contribute to a state of energy depletion and increased ROS generation, which compromises glucose uptake and increases the sensitivity of the heart to the toxic effects of chronic $\beta$-adrenergic signaling. This again 
assures the importance of STAT3 in cardioprotection against PPCM (150). Generally, cardiac glucose uptake and oxidation are decreased upon chronic stimulation with the $\beta$-adrenergic agonist isoproterenol. Cardiac myocytes mostly rely on glucose oxidation under these conditions, since isoproterenol depletes serum free fatty acids, and cardiac free fatty acids uptake. Evidence showed that inadequate glucose uptake by cardiac myocytes due to STAT3 loss was associated with increased mitochondrial ROS formation caused by insufficient NADPH generation needed to maintain adequate GSH recycling in mitochondria (2).

\section{STAT3 in Diabetic Cardiomyopathy}

Diabetes mellitus (DM) is one of the most prevalent diseases worldwide (151). Diabetic patients have a higher chance of developing cardiovascular complications due to the fact that diabetes exerts harmful effects on the cardiovascular system (152, 153). Diabetic cardiomyopathy (DCM) is defined by the presence of abnormal myocardial structure and performance in the absence of other cardiac risk factors in individuals with diabetes mellitus (154). Therefore, it is an independent complication of diabetes characterized by myocardial dysfunction. DCM is characterized by diastolic dysfunction caused by myocardial fibrosis which occurs in response to hyperglycemia (155).

Under non-ischemic cardiac conditions, the effect of diabetes on the expression, phosphorylation, and activation of cardiac STAT3 is controversial. On one hand, various papers have reported a decrease in cardiac STAT3 phosphorylation and activation in several diabetic experimental models. In this regard, Wang et al. showed that myocardial pS727-STAT3 activation was decreased in streptozotocin-induced type I diabetes (156). Using the same model, the same team later demonstrated that pY705-STAT3 phosphorylation was also decreased $(157,158)$. In addition to the diabetes I model, reduced expression of cardiac STAT3 has been reported in a type II diabetes model, where a downregulation of STAT3 mRNA was observed in rats (159). Along the same lines, exposing isolated adult rat cardiomyocytes to high glucose conditions induced a reduction in Y705-STAT3 phosphorylation and activation (160). Similarly, both Y705 and S727 STAT3 phosphorylation levels were significantly decreased in $\mathrm{H} 9 \mathrm{c} 2$ cells (rat cardiac myoblasts) subjected to high glucose conditions $(157,161)$.

On the other hand, other studies have reported that STAT3 phosphorylation was significantly increased in diabetic hearts. Hyperglycemia was shown to induce activation of STAT3 signaling pathway through JAK2 $(162,163)$. In diabetic rats, cardiac levels of p-JAK2 and p-STAT3 are significantly increased, accompanied to a significant increase in IL-6 and collagen deposition (162). In the same context, streptozotocin-induced diabetes resulted in cardiac STAT3 activation in C57BL/6 mice (164). Similar patterns were observed in a rat model of streptozotocin-induced diabetes (165). In agreement with these studies, an increased level of STAT3 phosphorylation was observed in Wistar rats following 21-weeks of high-fat and glucose diet (166). In addition to in vivo studies, STAT3 activation was also reported under high glucose conditions in H9c2 cells $(165,167)$ and rat cardiac fibroblasts $(143)$.
As previously discussed, STAT3 is known to be involved in the mechanisms of fibrosis, which is a prominent feature of DCM. Thus, studying involvement of STAT3 in myocardial fibrosis specifically during diabetes presents a particular prominent interest for understanding DCM. In this context, cardiac fibrosis was recently shown to be associated with increased matrix metalloproteinase-9 (MMP-9) expression in DCM (168). In addition, connective tissue growth factor (CTGF) expression was observed to be increased in different fibrotic disorders, mediating DCM development (169). As a transcription factor, STAT3 has been reported to regulate MMP9 and CTGF expression in diabetic rats with cardiac fibrosis, and suppression of STAT3 inhibited fibrosis (170).

Diabetes constitutes a prominent risk factor in the development of ischemic heart disease. Thus, the effect of $\mathrm{DM}$ on the sensitivity of the heart to IR injury is of major interest. Clinical studies have revealed that DM worsened long-term outcome of ischemic heart disease by increasing sensitivity to IR injury, but the acute outcome following IR injury remains controversial (153). In this regard, the infarct size was reported to be significantly increased, unchanged, or decreased in diabetic rats compared to controls $(156,157,171)$. Despite the contradictions in the effect on infarct size, the post-ischemic activation of cardiac STAT3 was reported to be reduced in all the investigations (153). In rat hearts subjected to IR, a reduction in pY705-STAT3 was observed in diabetic rats (172). In other in vivo studies, the same reduction was reported in different models $(156,157,160,173)$. With regard in vitro models, STAT3 inactivation was reported in cultured rat myocytes exposed to high glucose and hypoxia/reoxygenation (156). In addition, in cultured H9c2 cells exposed to high glucose and subjected to hypoxia/reoxygenation, pS727 STAT3 and pY705 STAT3 levels were decreased following ischemic injury (160).

In conclusion, the decrease in STAT3 phosphorylation/activation in post-ischemic hearts due to diabetes represents a definitive response regardless of the model. This might consequently lead to increased sensitivity to myocardial IR injury in diabetes. Thus, STAT3 might be considered in future therapies targeting the adverse effects of diabetic cardiomyopathy.

\section{STAT3 in Myocardial Infarction: Focus on Inflammation}

Myocardial infarction represents the most common form of acute cardiac injury. Among the variable mechanisms underlying myocardial IR injury, inflammation constitutes the hallmark of MI and reperfusion injury (174). The post-MI inflammatory response includes two phases. The first phase is characterized by the recruitment and infiltration of inflammatory cells to the infarcted area. The second phase comprises the resolution of inflammation (175). STAT3 plays roles in regulating cardiac remodeling following MI, partly through its involvement in the inflammatory response underlying this phenomenon (67). In this regard, STAT3 functions by interfering with the production of key inflammatory cytokines following MI (1), in the infiltration of neutrophils and monocytes to 
infarcted area (176), and in the regulation of macrophage polarization $(177,178)$.

\section{STAT3 in Inflammatory Cytokine Signaling}

STAT3 is a central signaling molecule for many cytokine receptors, including pro-inflammatory and anti-inflammatory ones. Thus, it participates in both inflammatory and noninflammatory responses downstream of cytokine activation. Following MI, and as a part of the pro-inflammatory response, an increased secretion of pro-inflammatory cytokines such as IL-6, IL-1 $\beta$, and TNF- $\alpha$ is observed (1).This increased secretion could be detrimental if it exceeds the acute phase. As already stated, STAT3 is acutely activated downstream of IL-6 via the gp-130 receptor, and this activation is regulated by subsequent inhibition by SOCS3 (179). In the context of inflammation following MI, a cardiomyocyte-specific mutation of the gp130 receptor in a mouse model lead to uncontrolled STAT3 activation, expectedly due to the interruption of the SOCS3 negative feedback loop (180). This was accompanied by a sustained cardiac inflammation in response to MI. Therefore, uncontrolled and continued gp130-STAT3 activation promotes cardiac inflammation following MI, suggesting a pathogenic role for high IL-6 levels and inflammation as a result of activated signaling pathways in MI (176).

On the gene expression level, evidence showed that the accumulation of non-phosphorylated STAT3 in the nucleus can induce the expression of pro-inflammatory genes, including IL$6(181)$.

On the other hand, and as part of the anti-inflammatory response, STAT3 is activated by IL-10. STAT3 activity by itself does not result in an anti-immune response. Instead, STAT3 activates expression effector genes that selectively repress sets of inflammatory genes such as TNF $\alpha$, IL-12p 40 , IL- $1 \alpha$, IL- $1 \beta$, IL$6(182,183)$. In short, later STAT3 activation, linked to IL-10, is beneficial and anti-inflammatory; however, initial brief STAT3 activation, linked to IL-6, is pro-inflammatory and harmful if too robust.

\section{STAT3 in Neutrophil/Macrophage Recruitment}

IL-6 represents an important checkpoint regulator of neutrophil trafficking during the inflammatory response by orchestrating chemokine production and leukocyte apoptosis. In a study that aimed to understand the receptor-mediated signaling events responsible for IL-6-driven neutrophil trafficking, Fielding et al. demonstrated that hyper-activation of STAT3 in mice with a global gp130 knock-in mutation that does not bind SOCS3 resulted in a more rapid clearance of neutrophils, and this coincided with decreased production of the neutrophil-attracting chemokine CXCL1. Thus, the IL-6-driven signaling via STAT3 controls the clearance of inflammatory neutrophils (176). The apparent discrepancy between cardiac-targeted (discussed above) vs. global gp130-mediated STAT3 hyperactivation in sustaining or restraining an inflammatory response highlights the need to better understand the role of STAT3 activation in a cell-specific and context-dependent manner.

Granulocyte colony-stimulating factor (G-CSF), a key mediator of neutrophil infiltration, is significantly increased and can be induced by angiotensin II. In a mouse study, angiotensin II infusion lead to a significant increase in G-CSF, along with a neutrophil accumulation, pro-inflammatory cytokine expression, reactive oxygen species production and cardiac fibrosis via activation of STAT3, ERK1/2, and AKT signaling pathways (126).

STAT3 plays a role in the recruitment of macrophages. This process is facilitated by Reg3b secretion from cardiac myocytes in response to the gp130-family cytokine oncostatin M (OSM), and STAT3 was demonstrated to be required for the expression of Reg3b (184).

\section{STAT3 in Macrophage Polarization}

Macrophages are major effector cells in tissue repair and fibrosis. They can be broadly categorized as M1 and M2. M1 macrophages are pro-inflammatory, expressing inflammatory genes, including iNOS. In contrast, M2 macrophages are involved in the resolution of inflammation and secrete arginase- 1 and IL10 (177). Accumulating evidence shows that STAT3 plays key roles in determining the polarization of macrophages to the M2 phenotype (178).

In this context, the IL-10-galectin-3 axis was recently shown to be essential for the M2 macrophage polarization after myocardial infarction in a STAT3-dependent manner, and these macrophages contributed to tissue repair by promoting fibrosis and clearance of apoptotic cells (185). In another recent study, sodium-glucose cotransporter2 (SGLT2) inhibitors mediated M2c polarization by regulating reactive oxygen and nitrogen species production through a STAT3-mediated pathway (186). Similarly, Lee et al. demonstrated that a STAT3dependent pathway in post-infarcted rats regulates macrophages phenotype (177).

Overall, STAT3 plays pivotal roles in regulating the cardiac response during myocardial infarction, partly through regulating inflammation. It interferes in the pro-inflammatory and antiinflammatory responses, whereby STAT3 is first activated downstream of inflammatory cytokines and then regulates the infiltration of immune cells to the injured area.

\section{STAT3 in Doxorubicin-Mediated Cardiotoxicity}

Doxorubicin (Dox) is an important anticancer agents. However, its clinical application is limited by severe cardiotoxicity (187). Various mechanisms are suggested to be involved in Doxinduced heart failure. They include DNA intercalation, free radical generation, and damage to cell membranes. Many studies support the notion that oxidative stress plays a significant role in the pathogenesis of Dox-induced cardiotoxicity (188). STAT3 has been shown to be involved in cardioprotection against Dox, whereby the overexpression of STAT3 in the heart was shown to be protective against Dox-induced cardiomyopathy (131). One proposed mechanism is through regulating the expression of the anti-oxidative proteins metallothionein 1 and 2 (MT1 and MT2); the JAK2/STAT3 pathway was reported to be partially involved in the MT-mediated protection against Dox-induced cardiotoxicity (187). In addition, another study showed that $S$ propargyl-cysteine (SPRC), a source of endogenous hydrogen 
sulfide $\left(\mathrm{H}_{2} \mathrm{~S}\right)$, possesses cardioprotective efficacy against Dox by stimulating the activation of STAT3 via gp130-mediated signaling in vitro and in vivo. In Dox-stimulated cardiotoxicity, SPRC enhanced cell viability, restored expression of gp130/STAT3regulated downstream genes, inhibited apoptosis and oxidative stress, and antagonized mitochondrial dysfunction. All of these beneficial effects of SPRC were lost by blocking the gp130/STAT3 signaling (33).

\section{CONCLUSION AND PERSPECTIVES}

STAT3 represents a crucial molecule for the maintenance of heart function, under physiological and pathological conditions. The pathological conditions in which STAT3 is involved include myocardial infarction, diabetic cardiomyopathy, peripartum cardiomyopathy, fibrosis, and hypertrophy. This involvement of STAT3 is mainly mediated through its functioning as a transcription factor able to regulate a wide array of genes. However, several functions are still controversial and need to be better understood in order to guide future therapeutic strategies against these pathologies. The roles played by STAT3 in autophagy, metabolism, and ER stress need to be better established in the context of the mentioned cardiac pathologies in order to link the abnormalities at the molecular and functional levels $(189,190)$. Moreover, the interplay between STAT3 and other signaling molecules needs to be deciphered for a better understanding of the regulators of STAT3 functions. In addition, the pattern of STAT3 distribution between mitochondria, ER and MAMs needs to be investigated under physiological and pathological conditions. In the context of inflammation, the involvement of STAT3 in regulating the inflammatory response needs to be studied under protective conditions, not only pathologic conditions, in order to investigate if STAT3 induces cardioprotection by regulating inflammation.

The level of STAT3 activation in the heart likely determines whether its actions are beneficial, harmful, or a combination of the two. For instance, transgenic mice with cardiac-specific overexpression of a constitutively active STAT3, which produces low levels of continuous activation, demonstrated evidence for VEGF induction in the heart (71).On the other hand, while protecting against DOX-induced cardiomyopathy via the induction of protective factors, cardiac-specific overexpression of STAT3 resulted in clear evidence for pathological hypertrophy (131). Additionally, co-factors and post-translational modifications, as well as its subcellular localization (e.g., mitochondria), are likely important in determining the flavor of increased STAT3 activation.

Therapeutically, understanding the mechanisms underlying a pathology represents the first step toward discovering preventive or treatment protocols and medications against this pathology. Since STAT3 is involved in a wide range of physiological and pathological cardiac conditions, understanding the mechanisms of this involvement paves the way toward finding therapeutic strategies involving either the inhibition or activation of STAT3. By describing the different roles of STAT3 as a transcription factor and a signaling molecule, and through explaining its upstream activation, the current review highlights several targets for therapeutic approaches. This may include pharmacological activation or inhibition of STAT3, respectively achieved by inducing the secretion of upstream activators (such as cytokines or growth factors) or developing direct pharmacological inhibitors with non-toxic side effects.

\section{AUTHOR CONTRIBUTIONS}

All authors have equally contributed to the writing of the manuscript and have approved the final version for submission.

\section{FUNDING}

This study benefits from grants offered by INSERM, the Lebanese University and the Cedar program of Campus France (\#37303QA 2017-2018). This work was supported by the IHU OPeRa (ANR10-IBHU-004) within the program Investissements d'Avenir operated by the French National Research Agency (ANR). $\mathrm{ZH}$ was supported by the Association de Specialisation et d'orientation Scientifique and by the Fondation Leducq ( ${ }^{\circ}$ 16CVD04: Mitocardia Network) through MO.

\section{REFERENCES}

1. O’Sullivan KE, Breen EP, Gallagher HC, Buggy DJ, Hurley JP. Understanding STAT3 signaling in cardiac ischemia. Basic Res Cardiol. (2016) 111:27. doi: 10.1007/s00395-016-0543-8

2. Kurdi M, Zgheib C, Booz GW. Recent developments on the crosstalk between STAT3 and inflammation in heart function and disease. Front Immunol. (2018) 9:3029. doi: 10.3389/fimmu.2018.03029

3. Zammarchi F, de Stanchina E, Bournazou E, Supakorndej T, Martires $\mathrm{K}$, Riedel E, et al. Antitumorigenic potential of STAT3 alternative splicing modulation. Proc Natl Acad Sci USA. (2011) 108:17779-84. doi: 10.1073/pnas.1108482108

4. Qi Q-R, Yang Z-M. Regulation and function of signal transducer and activator of transcription 3. World J Biol Chem. (2014) 5:231-9. doi: 10.4331/wjbc.v5.i2.231

5. Zouein FA, Altara R, Chen Q, Lesnefsky EJ, Kurdi M, Booz GW. Pivotal importance of STAT3 in protecting the heart from acute and chronic stress:

new advancement and unresolved issues. Front Cardiovasc Med. (2015) 2:36. doi: $10.3389 /$ fcvm.2015.00036

6. Schindler C. JAK-STAT signaling in human disease. J Clin Invest. (2002) 109:7. doi: 10.1172/JCI0215644

7. Niu J, Sun Y, Chen B, Zheng B, Jarugumilli GK, Walker SR, et al. Fatty acids and cancer-amplified ZDHHC19 promote STAT3 activation through Spalmitoylation. Nature. (2019) 573:139-43. doi: 10.1038/s41586-019-1511-x

8. Argetsinger LS, Campbell GS, Yang X, Witthuhn BA, Silvennoinen O, Ihle $\mathrm{JN}$, et al. Identification of JAK2 as a growth hormone receptor-associated tyrosine kinase. Cell. (1993) 74:237-44. doi: 10.1016/0092-8674(93) 90415-M

9. Parganas E, Wang D, Stravopodis D, Topham DJ, Marine JC, Teglund S, et al. Jak2 is essential for signaling through a variety of cytokine receptors. Cell. (1998) 93:385-95. doi: 10.1016/S0092-8674(00)81167-8

10. Bromberg JF. Activation of STAT proteins and growth control. Bio Essays News Rev Mol Cell Dev Biol. (2001) 23:161-9. doi: 10.1002/15211878(200102)23:2<161::AID-BIES1023>3.0.CO;2-0 
11. Bowman T, Garcia R, Turkson J, Jove R. STATs in oncogenesis. Oncogene. (2000) 19:2474-88. doi: 10.1038/sj.onc.1203527

12. Zhong Z, Wen Z, Darnell JE. Stat3: a STAT family member activated by tyrosine phosphorylation in response to epidermal growth factor and interleukin-6. Science. (1994) 264:95-8. doi: 10.1126/science.8140422

13. Zhang X, Blenis J, Li HC, Schindler C, Chen-Kiang S. Requirement of serine phosphorylation for formation of STAT-promoter complexes. Science. (1995) 267:1990-4. doi: 10.1126/science.7701321

14. Wen Z, Zhong Z, Darnell JE. Maximal activation of transcription by statl and stat3 requires both tyrosine and serine phosphorylation. Cell. (1995)82:24150. doi: 10.1016/0092-8674(95)90311-9

15. Wen Z, Darnell JE. Mapping of Stat3 serine phosphorylation to a single residue (727) and evidence that serine phosphorylation has no influence on DNA binding of Stat1 and Stat3. Nucleic Acids Res. (1997) 25:2062-7. doi: 10.1093/nar/25.11.2062

16. Aggarwal BB, Kunnumakkara AB, Harikumar KB, Gupta SR, Tharakan ST, Koca $C$, et al. Signal transducer and activator of transcription-3, inflammation, and cancer: how intimate is the relationship? Ann N Y Acad Sci. (2009)1171:59-76. doi: 10.1111/j.1749-6632.2009.04911.x

17. Chung J, Uchida E, Grammer TC, Blenis J. STAT3 serine phosphorylation by ERK-dependent and -independent pathways negatively modulates its tyrosine phosphorylation. Mol Cell Biol. (1997)17:6508-16. doi: 10.1128/MCB.17.11.6508

18. Jain N, Zhang T, Fong SL, Lim CP, Cao X. Repression of Stat3 activity by activation of mitogen-activated protein kinase (MAPK). Oncogene. (1998)17:3157-67. doi: 10.1038/sj.onc.1202238

19. Boengler K, Hilfiker-Kleiner D, Drexler H, Heusch G, Schulz R. The myocardial JAK/STAT pathway: from protection to failure. Pharmacol Ther. (2008) 120:172-85. doi: 10.1016/j.pharmthera.2008.08.002

20. Lim CP, Cao X. Regulation of Stat3 Activation by MEK Kinase 1. J Biol Chem. (2001) 276:21004-11. doi: 10.1074/jbc.M007592200

21. Lejay A, Fang F, John R, Van JAD, Barr M, Thaveau F, et al. Ischemia reperfusion injury, ischemic conditioning and diabetes mellitus. J Mol Cell Cardiol. (2016)91:11-22. doi: 10.1016/j.yjmcc.2015.12.020

22. Liu Z, Hsu H, Goeddel DV, Karin M. Dissection of TNF receptor 1 effector functions: JNK activation is not linked to apoptosis while NF-kappaB activation prevents cell death. Cell. (1996) 87:565-76. doi: 10.1016/S0092-8674(00)81375-6

23. Qiu H, Lizano P, Laure L, Sui X, Rashed E, Park JY, et al. H11 kinase/heat shock protein 22 deletion impairs both nuclear and mitochondrial functions of STAT3 and accelerates the transition into heart failure on cardiac overload. Circulation. (2011)124:406-15. doi: 10.1161/CIRCULATIONAHA.110.013847

24. Ray S, Boldogh I, Brasier AR. STAT3 NH2-terminal acetylation is activated by the hepatic acute-phase response and required for IL6 induction of angiotensinogen. Gastroenterology. (2005)129:1616-32. doi: $10.1053 /$ j.gastro.2005.07.055

25. Ray S, Lee C, Hou T, Boldogh I, Brasier AR. Requirement of histone deacetylase1 (HDAC1) in signal transducer and activator of transcription 3 (STAT3) nucleocytoplasmic distribution. Nucleic Acids Res. (2008)36:451020. doi: $10.1093 / \mathrm{nar} / \mathrm{gkn} 419$

26. Yuan Z-L, Guan Y-J, Chatterjee D, Chin YE. Stat3 dimerization regulated by reversible acetylation of a single lysine residue. Science. (2005) 307:269-73. doi: $10.1126 /$ science. 1105166

27. Wang R, Cherukuri P, Luo J. Activation of Stat3 sequence-specific DNA binding and transcription by p300/CREB-binding protein-mediated acetylation. J Biol Chem. (2005) 280:11528-34. doi: 10.1074/jbc.M413 930200

28. Jain S, Wei J, Mitrani LR, Bishopric NH. Auto-acetylation stabilizes p300 in cardiac myocytes during acute oxidative stress, promoting STAT3 accumulation and cell survival. Breast Cancer Res Treat. (2012)135:103-14. doi: 10.1007/s10549-012-2069-6

29. Lima B, Forrester MT, Hess DT, Stamler JS. S-Nitrosylation in cardiovascular signaling. Circ Res. (2010) 106:633-46. doi: 10.1161/CIRCRESAHA.109.207381

30. Kim J, Won J-S, Singh AK, Sharma AK, Singh I. STAT3 regulation by Snitrosylation: implication for inflammatory disease. Antioxid Redox Signal. (2014) 20:2514-27. doi: 10.1089/ars.2013.5223
31. Ju Y, Fu M, Stokes E, Wu L, Yang G. $\mathrm{H}_{2} \mathrm{~S}$-mediated protein S-sulfhydration: a prediction for its formation and regulation. Molecules. (2017) 22:E1334. doi: 10.3390/molecules 22081334

32. Polhemus DJ, Lefer DJ. Emergence of hydrogen sulfide as an endogenous gaseous signaling molecule in cardiovascular disease. Circ Res. (2014) 114:730-7. doi: 10.1161/CIRCRESAHA.114.300505

33. Wu J, Guo W, Lin S-Z, Wang Z-J, Kan J-T, Chen S-Y, et al. Gp130-mediated STAT3 activation by S-propargyl-cysteine, an endogenous hydrogen sulfide initiator, prevents doxorubicin-induced cardiotoxicity. Cell Death Dis. (2016)7:e2339. doi: 10.1038/cddis.2016.209

34. Xin H, Wang M, Tang W, Shen Z, Miao L, Wu W, et al. Hydrogen sulfide attenuates inflammatory hepcidin by reducing IL-6 secretion and promoting SIRT1-mediated STAT3 deacetylation. Antioxid Redox Signal. (2016) 24:7083. doi: 10.1089 /ars. 2015.6315

35. Bhattacharya S, Schindler C. Regulation of Stat3 nuclear export. J Clin Invest. (2003)111:553-9. doi: 10.1172/JCI15372

36. Liu L, McBride KM, Reich NC. STAT3 nuclear import is independent of tyrosine phosphorylation and mediated by importin-alpha3. Proc Natl Acad Sci USA. (2005) 102:8150-5. doi: 10.1073/pnas.0501643102

37. Szczepanek K, Chen Q, Derecka M, Salloum FN, Zhang Q, Szelag M, et al. Mitochondrial-targeted signal transducer and activator of transcription 3 (STAT3) protects against ischemia-induced changes in the electron transport chain and the generation of reactive oxygen species. J Biol Chem. (2011) 286:29610-20. doi: 10.1074/jbc.M111.226209

38. Lecour S. Activation of the protective Survivor Activating Factor Enhancement (SAFE) pathway against reperfusion injury: does it go beyond the RISK pathway? J Mol Cell Cardiol. (2009)47:32-40. doi: 10.1016/j.yjmcc.2009.03.019

39. Bolli R, Stein AB, Guo Y, Wang O-L, Rokosh G, Dawn B, et al. A murine model of inducible, cardiac-specific deletion of STAT3: its use to determine the role of STAT3 in the upregulation of cardioprotective proteins by ischemic preconditioning. J Mol Cell Cardiol. (2011)50:589-97. doi: 10.1016/j.yjmcc.2011.01.002

40. Poli V, Camporeale A. STAT3-mediated metabolic reprograming in cellular transformation and implications for drug resistance. Front Oncol. (2015) 5:121. doi: $10.3389 /$ fonc.2015.00121

41. Demaria M, Camporeale A, Poli V. STAT3 and metabolism: how many ways to use a single molecule? STAT3 and metabolism. Int J Cancer. (2014) 135:1997-2003. doi: 10.1002/ijc.28767

42. Zouein FA, Kurdi M, Booz GW. Dancing rhinos in stilettos: the amazing saga of the genomic and nongenomic actions of STAT3 in the heart. JAK-STAT. (2013) 2:e24352. doi: 10.4161/jkst.24352

43. Zhou L, Too H-P. Mitochondrial localized STAT3 is involved in NGF induced neurite outgrowth. PLoS ONE. (2011) 6:e21680. doi: 10.1371 /journal.pone. 0021680

44. Heusch G, Musiolik J, Gedik N, Skyschally A. Mitochondrial STAT3 activation and cardioprotection by ischemic postconditioning in pigs with regional myocardial ischemia/reperfusion. Circ Res. (2011) 109:1302-8. doi: 10.1161/CIRCRESAHA.111.255604

45. Bernier M, Paul RK, Martin-Montalvo A, Scheibye-Knudsen M, Song $\mathrm{S}$, He H-J, et al. Negative regulation of STAT3 protein-mediated cellular respiration by SIRT1 protein. J Biol Chem. (2011) 286:19270-9. doi: 10.1074/jbc.M110.200311

46. Wegrzyn J, Potla R, Chwae Y-J, Sepuri NBV, Zhang Q, Koeck T, et al. Function of mitochondrial Stat3 in cellular respiration. Science. (2009) 323:793-7. doi: 10.1126/science.1164551

47. Gough DJ, Corlett A, Schlessinger K, Wegrzyn J, Larner AC, Levy DE. Mitochondrial STAT3 supports Ras-dependent oncogenic transformation. Science. (2009) 324:1713-6. doi: 10.1126/science.1171721

48. Boengler K, Hilfiker-Kleiner D, Heusch G, Schulz R. Inhibition of permeability transition pore opening by mitochondrial STAT3 and its role in myocardial ischemia/reperfusion. Basic Res Cardiol. (2010)105:771-85. doi: 10.1007/s00395-010-0124-1

49. Harhous Z, Badawi S, Bona NG, Pillot B, Augeul L, Paillard M, et al. Critical appraisal of STAT3 pattern in adult cardiomyocytes. J Mol Cell Cardiol. (2019) 131:91-100. doi: 10.1016/j.yjmcc.2019.04.021

50. Szczepanek K, Xu A, Hu Y, Thompson J, He J, Larner AC, et al. Cardioprotective function of mitochondrial-targeted and transcriptionally 
inactive STAT3 against ischemia and reperfusion injury. Basic Res Cardiol. (2015)110:53. doi: 10.1007/s00395-015-0509-2

51. Eltzschig HK, Eckle T. Ischemia and reperfusion-from mechanism to translation. Nat Med. (2011) 17:1391-401. doi: 10.1038/nm.2507

52. Eltzschig HK, Carmeliet P. Hypoxia and inflammation. N Engl J Med. (2011) 364:656-65. doi: 10.1056/NEJMra0910283

53. Eefting F, Rensing B, Wigman J, Pannekoek WJ, Liu WM, Cramer MJ, et al. Role of apoptosis in reperfusion injury. Cardiovasc Res. (2004) 61:414-26. doi: 10.1016/j.cardiores.2003.12.023

54. Olivetti G, Quaini F, Sala R, Lagrasta C, Corradi D, Bonacina E, et al. Acute myocardial infarction in humans is associated with activation of programmed myocyte cell death in the surviving portion of the heart. $J \mathrm{Mol}$ Cell Cardiol. (1996)28:2005-16. doi: 10.1006/jmcc.1996.0193

55. McCormick J, Barry SP, Sivarajah A, Stefanutti G, Townsend PA, Lawrence KM, et al. Free radical scavenging inhibits STAT phosphorylation following in vivo ischemia/reperfusion injury. FASEB J. (2006)20:2115-7. doi: 10.1096/fj.06-6188fje

56. Negoro S. Activation of JAK/STAT pathway transduces cytoprotective signal in rat acute myocardial infarction. Cardiovasc Res. (2000)47:797-805. doi: 10.1016/S0008-6363(00)00138-3

57. Hilfiker-Kleiner D, Hilfiker A, Fuchs M, Kaminski K, Schaefer A, Schieffer $\mathrm{B}$, et al. Signal transducer and activator of transcription 3 is required for myocardial capillary growth, control of interstitial matrix deposition, and heart protection from ischemic injury. Circ Res. (2004) 95:187-95. doi: 10.1161/01.RES.0000134921.50377.61

58. Yamauchi-Takihara K, Kishimoto T. A novel role for STAT3 in cardiac remodeling. Trends Cardiovasc Med. (2000) 10:298-303. doi: 10.1016/S1050-1738(01)00066-4

59. Omura T, Yoshiyama M, Ishikura F, Kobayashi H, Takeuchi K, Beppu S, et al. Myocardial ischemia activates the JAK-STAT pathway through angiotensin II signaling in in vivo myocardium of rats. J Mol Cell Cardiol. (2001)33:307-16. doi: $10.1006 / j m c c .2000 .1303$

60. Fuchs M, Hilfiker A, Kaminski K, Hilfiker-Kleiner D, Guener Z, Klein G, et al. Role of interleukin- 6 for LV remodeling and survival after experimental myocardial infarction. FASEB J. (2003)17:2118-20. doi: 10.1096/fj.03-0331fje

61. Fuglesteg BN, Suleman N, Tiron C, Kanhema T, Lacerda L, Andreasen $\mathrm{TV}$, et al. Signal transducer and activator of transcription 3 is involved in the cardioprotective signalling pathway activated by insulin therapy at reperfusion. Basic Res Cardiol. (2008)103:444-53. doi: $10.1007 /$ s00395-008-0728-x

62. Somers SJ, Frias M, Lacerda L, Opie LH, Lecour S. Interplay between SAFE and RISK pathways in sphingosine-1-phosphate-induced cardioprotection. Cardiovasc Drugs Ther. (2012)26:227-37. doi: 10.1007/s10557-012-6376-2

63. Meier JA, Hyun M, Cantwell M, Raza A, Mertens C, Raje V, et al. Stressinduced dynamic regulation of mitochondrial STAT3 and its association with cyclophilin D reduce mitochondrial ROS production. Sci Signal. (2017) 10:eaag2588. doi: 10.1126/scisignal.aag2588

64. Fujio Y, Maeda M, Mohri T, Obana M, Iwakura T, Hayama A, et al. Glycoprotein 130 cytokine signal as a therapeutic target against cardiovascular diseases. J Pharmacol Sci. (2011) 117:213-22. doi: 10.1254/jphs.11R05CR

65. Fischer P, Hilfiker-Kleiner D. Survival pathways in hypertrophy and heart failure: the gp130-STAT3 axis. Basic Res Cardiol. (2007)102:393-411. doi: 10.1007/s00395-007-0674-Z

66. Haghikia A, Stapel B, Hoch M, Hilfiker-Kleiner D. STAT3 and cardiac remodeling. Heart Fail Rev. (2011)16:35-47. doi: 10.1007/s10741-010-9170-x

67. Enomoto D, Obana M, Miyawaki A, Maeda M, Nakayama H, Fujio Y. Cardiac-specific ablation of the STAT3 gene in the subacute phase of myocardial infarction exacerbated cardiac remodeling. Am J Physiol Heart Circ Physiol. (2015) 309:H471-80. doi: 10.1152/ajpheart.00730.2014

68. Negoro S, Kunisada K, Fujio Y, Funamoto M, Darville MI, Eizirik DL, et al. Activation of signal transducer and activator of transcription 3 protects cardiomyocytes from hypoxia/reoxygenation-induced oxidative stress through the upregulation of manganese superoxide dismutase. Circulation. (2001) 104:979-81. doi: 10.1161/hc3401.095947

69. Oshima Y, Fujio Y, Nakanishi T, Itoh N, Yamamoto Y, Negoro S, et al. STAT3 mediates cardioprotection against ischemia/reperfusion injury through metallothionein induction in the heart. Cardiovasc Res. (2005) 65:428-35. doi: 10.1016/j.cardiores.2004.10.021

70. Boengler K, Ungefug E, Heusch G, Schulz R. The STAT3 inhibitor stattic impairs cardiomyocyte mitochondrial function through increased reactive oxygen species formation. Curr Pharm Des. (2013) 19:6890-5. doi: 10.2174/138161281939131127115940

71. Osugi T, Oshima Y, Fujio Y, Funamoto M, Yamashita A, Negoro S, et al. Cardiac-specific activation of signal transducer and activator of transcription 3 promotes vascular formation in the heart. J Biol Chem. (2002) 277:6676-81. doi: 10.1074/jbc.M108246200

72. Haghikia A, Missol-Kolka E, Tsikas D, Venturini L, Brundiers S, Castoldi $\mathrm{M}$, et al. Signal transducer and activator of transcription 3-mediated regulation of miR-199a-5p links cardiomyocyte and endothelial cell function in the heart: a key role for ubiquitin-conjugating enzymes. Eur Heart J. (2011)32:1287-97. doi: 10.1093/eurheartj/ehq369

73. Hausenloy DJ, Lecour S, Yellon DM. Reperfusion injury salvage kinase and survivor activating factor enhancement prosurvival signaling pathways in ischemic postconditioning: two sides of the same coin. Antioxid Redox Signal. (2011)14:893-907. doi: 10.1089/ars.2010.3360

74. Heusch G. Molecular basis of cardioprotection: signal transduction in ischemic pre-, post-, and remote conditioning. Circ Res. (2015) 116:674-99. doi: 10.1161/CIRCRESAHA.116.305348

75. Xuan YT, Guo Y, Han H, Zhu Y, Bolli R. An essential role of the JAKSTAT pathway in ischemic preconditioning. Proc Natl Acad Sci USA. (2001) 98:9050-5. doi: 10.1073/pnas.161283798

76. Smith RM, Suleman N, Lacerda L, Opie LH, Akira S, Chien KR, et al. Genetic depletion of cardiac myocyte STAT-3 abolishes classical preconditioning. Cardiovasc Res. (2004) 63:611-6. doi: 10.1016/j.cardiores.2004.06.019

77. Boengler K, Buechert A, Heinen Y, Roeskes C, Hilfiker-Kleiner D, Heusch G, et al. Cardioprotection by ischemic postconditioning is lost in aged and STAT3-deficient mice. Circ Res. (2008) 102:131-5. doi: 10.1161/CIRCRESAHA.107.164699

78. You L, Li L, Xu Q, Ren J, Zhang F. Postconditioning reduces infarct size and cardiac myocyte apoptosis via the opioid receptor and JAK-STAT signaling pathway. Mol Biol Rep. (2011)38:437-43. doi: 10.1007/s11033-010-0126-y

79. Hattori R, Maulik N, Otani H, Zhu L, Cordis G, Engelman RM, et al. Role of STAT3 in ischemic preconditioning. J Mol Cell Cardiol. (2001)33:1929-36. doi: 10.1006/jmcc.2001.1456

80. Suleman N, Somers S, Smith R, Opie LH, Lecour SC. Dual activation of STAT-3 and Akt is required during the trigger phase of ischaemic preconditioning. Cardiovasc Res. (2008) 79:127-33. doi: 10.1093/cvr/cvn067

81. Wang Y, Wang D, Zhang L, Ye F, Li M, Wen K. Role of JAKSTAT pathway in reducing cardiomyocytes hypoxia/reoxygenation injury induced by S1P postconditioning. Eur J Pharmacol. (2016) 784:129-36. doi: 10.1016/j.ejphar.2016.05.024

82. Goodman MD, Koch SE, Fuller-Bicer GA, Butler KL. Regulating RISK: a role for JAK-STAT signaling in postconditioning? Am J Physiol-Heart Circ Physiol. (2008)295:H1649-56. doi: 10.1152/ajpheart.00692.2008

83. Tian Y, Zhang W, Xia D, Modi P, Liang D, Wei M. Postconditioning inhibits myocardial apoptosis during prolonged reperfusion via a JAK2-STAT3-Bcl-2 pathway. J Biomed Sci. (2011) 18:53. doi: 10.1186/1423-0127-18-53

84. Wu J, Yu J, Xie P, Maimaitili Y, Wang J, Yang L, et al. Sevoflurane postconditioning protects the myocardium against ischemia/reperfusion injury via activation of the JAK2-STAT3 pathway. PeerJ. (2017) 5:e3196. doi: $10.7717 /$ peerj.3196

85. Xuan Y-T, Guo Y, Zhu Y, Han H, Langenbach R, Dawn B, et al. Mechanism of cyclooxygenase-2 upregulation in late preconditioning. J Mol Cell Cardiol. (2003)35:525-37. doi: 10.1016/S0022-2828(03)00076-2

86. Yang Y, Hu W, Di S, Ma Z, Fan C, Wang D, et al. Tackling myocardial ischemic injury: the signal transducer and activator of transcription 3 (STAT3) at a good site. Expert Opin Ther Targets. (2017)21:215-28. doi: 10.1080/14728222.2017.1275566

87. Elschami M, Scherr M, Philippens B, Gerardy-Schahn R. Reduction of STAT3 expression induces mitochondrial dysfunction and autophagy in cardiac HL-1 cells. Eur J Cell Biol. (2013)92:21-9. doi: 10.1016/j.ejcb.2012.09.002

88. Ge W, Ren J. mTOR-STAT3-notch signalling contributes to ALDH2induced protection against cardiac contractile dysfunction and 
autophagy under alcoholism. J Cell Mol Med. (2012)16:616-26. doi: 10.1111/j.1582-4934.2011.01347.x

89. You L, Wang Z, Li H, Shou J, Jing Z, Xie J, et al. The role of STAT3 in autophagy. Autophagy. (2015) 11:729-39. doi: 10.1080/15548627.2015.1017192

90. Chen L, Zhao L, Samanta A, Mahmoudi SM, Buehler T, Cantilena A, et al. STAT3 balances myocyte hypertrophy vis-à-vis autophagy in response to Angiotensin II by modulating the AMPK $\alpha / \mathrm{mTOR}$ axis. PLoS ONE. (2017) 12:e0179835. doi: 10.1371/journal.pone.0179835

91. Jonchère B, Bélanger $A$, Guette $\mathrm{C}$, Barré $\mathrm{B}$, Coqueret $\mathrm{O}$. STAT3 as a new autophagy regulator. JAK-STAT. (2013) 2:e24353. doi: 10.4161/jkst.24353

92. Whelan RS, Kaplinskiy V, Kitsis RN. Cell death in the pathogenesis of heart disease: mechanisms and significance. Annu Rev Physiol. (2010) 72:19-44. doi: 10.1146/annurev.physiol.010908.163111

93. Minamino T, Komuro I, Kitakaze M. Endoplasmic reticulum stress as a therapeutic target in cardiovascular disease. Circ Res. (2010) 107:1071-82. doi: 10.1161/CIRCRESAHA.110.227819

94. Avalle L, Camporeale A, Morciano G, Caroccia N, Ghetti E, Orecchia V, et al. STAT3 localizes to the ER, acting as a gatekeeper for ER-mitochondrion $\mathrm{Ca}^{2+}$ fluxes and apoptotic responses. Cell Death Differ. (2018) 26:932-942. doi: 10.1038/s41418-018-0171-y

95. Li Y, Zhu W, Tao J, Xin P, Liu M, Li J, et al. Fasudil protects the heart against ischemia-reperfusion injury by attenuating endoplasmic reticulum stress and modulating SERCA activity: the differential role for PI3K/Akt and JAK2/STAT3 signaling pathways. PLOS ONE. (2012) 7:e48115. doi: 10.1371/journal.pone.0048115

96. Zhao G, Yu L, Gao W, Duan W, Jiang B, Liu X, et al. Berberine protects rat heart from ischemia/reperfusion injury via activating JAK2/STAT3 signaling and attenuating endoplasmic reticulum stress. Acta Pharmacol Sin. (2016)37:354-67. doi: 10.1038/aps.2015.136

97. Banerjee K, Keasey MP, Razskazovskiy V, Visavadiya NP, Jia C, Hagg T. Reduced FAK-STAT3 signaling contributes to ER stress-induced mitochondrial dysfunction and death in endothelial cells. Cell Signal. (2017)36:154-62. doi: 10.1016/j.cellsig.2017.05.007

98. Wang M, Meng X, Yu Y, Sun G, Xu X, Zhang X, et al. Elatoside C protects against hypoxia/reoxygenation-induced apoptosis in H9c2 cardiomyocytes through the reduction of endoplasmic reticulum stress partially depending on STAT3 activation. Apoptosis. (2014)19:1727-35. doi: 10.1007/s10495-014-1039-3

99. Warburg O. On respiratory impairment in cancer cells. Science. (1956) 124:269-70.

100. Darnell JE. STAT3, HIF-1, glucose addiction and Warburg effect. Aging. (2010) 2:890-1. doi: 10.18632/aging.100239

101. Semenza GL, Roth PH, Fang HM, Wang GL. Transcriptional regulation of genes encoding glycolytic enzymes by hypoxia-inducible factor 1. J Biol Chem. (1994) 269:23757-63.

102. Demaria M, Giorgi C, Lebiedzinska M, Esposito G, D’Angeli L, Bartoli A, et al. A STAT3-mediated metabolic switch is involved in tumour transformation and STAT3 addiction. Aging. (2010) 2:823-42. doi: 10.18632/aging.100232

103. Demaria M, Poli V. PKM2, STAT3 and HIF-1 $\alpha$ : the Warburg's vicious circle. JAK-STAT. (2012) 1:194. doi: 10.4161/jkst.20662

104. Niu G, Briggs J, Deng J, Ma Y, Lee H, Kortylewski M, et al. Signal transducer and activator of transcription 3 is required for hypoxiainducible factor-1alpha RNA expression in both tumor cells and tumorassociated myeloid cells. Mol Cancer Res MCR. (2008)6:1099-105. doi: 10.1158/1541-7786.MCR-07-2177

105. Xu Q, Briggs J, Park S, Niu G, Kortylewski M, Zhang S, et al. Targeting Stat3 blocks both HIF-1 and VEGF expression induced by multiple oncogenic growth signaling pathways. Oncogene. (2005) 24:555260. doi: 10.1038/sj.onc.1208719

106. Anglesio MS, George J, Kulbe H, Friedlander M, Rischin D, Lemech C, et al. IL6-STAT3-HIF signaling and therapeutic response to the angiogenesis inhibitor sunitinib in ovarian clear cell cancer. Clin Cancer Res Off J Am Assoc Cancer Res. (2011) 17:2538-48. doi: 10.1158/1078-0432.CCR-10-3314

107. Jung JE, Lee HG, Cho IH, Chung DH, Yoon S-H, Yang YM, et al. STAT3 is a potential modulator of HIF-1-mediated VEGF expression in human renal carcinoma cells. FASEB J. (2005)19:1296-8. doi: 10.1096/fj.04-3099fje
108. Cho KH, Choi MJ, Jeong KJ, Kim JJ, Hwang MH, Shin SC, et al. A ROS/STAT3/HIF- $1 \alpha$ signaling cascade mediates EGF-induced TWIST1 expression and prostate cancer cell invasion. Prostate. (2014)74:528-36. doi: $10.1002 /$ pros. 22776

109. Abdurrachim D, Luiken JJFP, Nicolay K, Glatz JFC, Prompers JJ, Nabben M. Good and bad consequences of altered fatty acid metabolism in heart failure: evidence from mouse models. Cardiovasc Res. (2015) 106:194-205. doi: $10.1093 / \mathrm{cvr} / \mathrm{cvv} 105$

110. Kundu BK, Zhong M, Sen S, Davogustto G, Keller SR, Taegtmeyer H. Remodeling of glucose metabolism precedes pressure overload-induced left ventricular hypertrophy: review of a hypothesis. Cardiology. (2015) 130:21120. doi: $10.1159 / 000369782$

111. Lv J, Deng C, Jiang S, Ji T, Yang Z, Wang Z, et al. Blossoming 20: the energetic regulator's birthday unveils its versatility in cardiac diseases. Theranostics. (2019) 9:466-76. doi: 10.7150/thno.29130

112. Lai L, Leone TC, Keller MP, Martin OJ, Broman AT, Nigro J, et al. Energy metabolic re-programming in the hypertrophied and early stage failing heart: a multi-systems approach. Circ Heart Fail. (2014)7:1022-31. doi: 10.1161/CIRCHEARTFAILURE.114.001469

113. Altara R, Harmancey R, Didion SP, Booz GW, Zouein FA. Cardiac STAT3 deficiency impairs contractility and metabolic homeostasis in hypertension. Front Pharmacol. (2016) 7:436. doi: 10.3389/fphar.2016.00436

114. Cooper G. Cytoskeletal networks and the regulation of cardiac contractility: microtubules, hypertrophy, and cardiac dysfunction. Am J Physiol-Heart Circ Physiol. (2006)291:H1003-14. doi: 10.1152/ajpheart.00132.2006

115. Tsutsui H, Ishihara K, Cooper G. Cytoskeletal role in the contractile dysfunction of hypertrophied myocardium. Science. (1993) 260:682-7. doi: $10.1126 /$ science. 8097594

116. Watkins SC, Samuel JL, Marotte F, Bertier-Savalle B, Rappaport L. Microtubules and desmin filaments during onset of heart hypertrophy in rat: a double immunoelectron microscope study. Circ Res. (1987) 60:327-36. doi: 10.1161/01.RES.60.3.327

117. Webster DR. Microtubules in cardiac toxicity and disease. Cardiovasc Toxicol. (2002) 2:75-89. doi: 10.1385/CT:2:2:075

118. Yan B, Xie S, Liu Z, Luo Y, Zhou J, Li D, et al. STAT3 association with microtubules and its activation are independent of HDAC6 activity. DNA Cell Biol. (2015)34:290-5. doi: 10.1089/dna.2014.2713

119. Ng DCH, Lin BH, Lim CP, Huang G, Zhang T, Poli V, et al. Stat3 regulates microtubules by antagonizing the depolymerization activity of stathmin. $J$ Cell Biol. (2006) 172:245-57. doi: 10.1083/jcb.200503021

120. Verma NK, Dourlat J, Davies AM, Long A, Liu W-Q, Garbay C, et al. STAT3stathmin interactions control microtubule dynamics in migrating T-cells. $J$ Biol Chem. (2009) 284:12349-62. doi: 10.1074/jbc.M807761200

121. Zhang W, Qu X, Chen B, Snyder M, Wang M, Li B, et al. Critical roles of STAT3 in $\beta$-adrenergic functions in the heart. Circulation. (2016) 133:48-61. doi: 10.1161/CIRCULATIONAHA.115.017472

122. Ng DCH, Ng IHW, Yeap YYC, Badrian B, Tsoutsman T, McMullen JR, et al. Opposing actions of extracellular signal-regulated kinase (ERK) and signal transducer and activator of transcription 3 (STAT3) in regulating microtubule stabilization during cardiac hypertrophy. J Biol Chem. (2011) 286:1576-87. doi: 10.1074/jbc.M110.128157

123. Wu Y-S, Chen C-C, Chien C-L, Lai H-L, Jiang S-T, Chen Y-C, et al. The type VI adenylyl cyclase protects cardiomyocytes from $\beta$-adrenergic stress by a PKA/STAT3-dependent pathway. J Biomed Sci. (2017) 24:68. doi: 10.1186/s12929-017-0367-3

124. Pan J, Fukuda K, Saito M, Matsuzaki J, Kodama H, Sano M, et al. Mechanical stretch activates the JAK/STAT pathway in rat cardiomyocytes. Circ Res. (1999) 84:1127-36. doi: 10.1161/01.RES.84.10.1127

125. Beckles DL, Mascareno E, Siddiqui MA. Inhibition of Jak2 phosphorylation attenuates pressure overload cardiac hypertrophy. Vascul Pharmacol. (2006)45:350-7. doi: 10.1016/j.vph.2006.05.006

126. Jacoby JJ, Kalinowski A, Liu M-G, Zhang SS-M, Gao Q, Chai G-X, et al. Cardiomyocyte-restricted knockout of STAT3 results in higher sensitivity to inflammation, cardiac fibrosis, and heart failure with advanced age. Proc Natl Acad Sci USA. (2003) 100:12929-34. doi: 10.1073/pnas.2134694100

127. Mascareno E, Siddiqui MA. The role of Jak/STAT signaling in heart tissue renin-angiotensin system. Mol Cell Biochem. (2000)212:171-5. doi: 10.1007/978-1-4615-4351-0_19 
128. Pan J, Fukuda K, Kodama H, Makino S, Takahashi T, Sano M, et al. Role of angiotensin II in activation of the JAK/STAT pathway induced by acute pressure overload in the rat heart. Circ Res. (1997)81:611-7. doi: 10.1161/01.RES.81.4.611

129. Kodama H, Fukuda K, Pan J, Makino S, Baba A, Hori S, et al. Leukemia inhibitory factor, a potent cardiac hypertrophic cytokine, activates the JAK/STAT pathway in rat cardiomyocytes. Circ Res. (1997)81:656-63. doi: 10.1161/01.RES.81.5.656

130. Mir SA, Chatterjee A, Mitra A, Pathak K, Mahata SK, Sarkar S. Inhibition of signal transducer and activator of transcription 3 (STAT3) attenuates interleukin-6 (IL-6)-induced collagen synthesis and resultant hypertrophy in rat heart. J Biol Chem. (2012) 287:2666-77. doi: 10.1074/jbc.M111. 246173

131. Kunisada K, Negoro S, Tone E, Funamoto M, Osugi T, Yamada S, et al. Signal transducer and activator of transcription 3 in the heart transduces not only a hypertrophic signal but a protective signal against doxorubicininduced cardiomyopathy. Proc Natl Acad Sci USA. (2000) 97:315-9. doi: $10.1073 /$ pnas.97.1.315

132. Uozumi H, Hiroi Y, Zou Y, Takimoto E, Toko H, Niu P, et al. gp130 plays a critical role in pressure overload-induced cardiac hypertrophy. J Biol Chem. (2001) 276:23115-9. doi: 10.1074/jbc.M100814200

133. Yasukawa H, Hoshijima M, Gu Y, Nakamura T, Pradervand S, Hanada T, et al. Suppressor of cytokine signaling-3 is a biomechanical stress-inducible gene that suppresses gp130-mediated cardiac myocyte hypertrophy and survival pathways. J Clin Invest. (2001) 108:1459-67. doi: 10.1172/JC I13939

134. Willey CD, Palanisamy AP, Johnston RK, Mani SK, Shiraishi H, Tuxworth WJ, et al. STAT3 activation in pressure-overloaded feline myocardium: role for integrins and the tyrosine kinase BMX. Int J Biol Sci. (2008) 4:184-99. doi: $10.7150 /$ ijbs.4.184

135. González GE, Rhaleb N-E, D’ambrosio MA, Nakagawa P, Liu Y, Leung P, et al. Deletion of interleukin-6 prevents cardiac inflammation, fibrosis and dysfunction without affecting blood pressure in angiotensin II-high salt-induced hypertension. J Hypertens. (2015)33:144-52. doi: 10.1097/HJH.0000000000000358

136. Zgheib C, Zouein FA, Kurdi M, Booz GW. Chronic treatment of mice with leukemia inhibitory factor does not cause adverse cardiac remodeling but improves heart function. Eur Cytokine Netw. (2012) 23:1917. doi: 10.1684/ecn.2012.0319

137. Hilfiker-Kleiner D, Kaminski K, Podewski E, Bonda T, Schaefer A, Sliwa K, et al. A cathepsin D-cleaved $16 \mathrm{kDa}$ form of prolactin mediates postpartum cardiomyopathy. Cell. (2007) 128:589-600. doi: 10.1016/j.cell.2006. 12.036

138. Yang Z, Jiang S, Shang J, Jiang Y, Dai Y, Xu B, et al. LncRNA: Shedding light on mechanisms and opportunities in fibrosis and aging. Ageing Res Rev. (2019)52:17-31. doi: 10.1016/j.arr.2019.04.001

139. Krenning G, Zeisberg EM, Kalluri R. The origin of fibroblasts and mechanism of cardiac fibrosis. J Cell Physiol. (2010)225:631-7. doi: $10.1002 /$ jcp. 22322

140. Meléndez GC, McLarty JL, Levick SP, Du Y, Janicki JS, Brower GL. Interleukin 6 mediates myocardial fibrosis, concentric hypertrophy, and diastolic dysfunction in rats. Hypertension. (2010)56:225-31. doi: 10.1161/HYPERTENSIONAHA.109.148635

141. Tsai C-T, Lai L-P, Kuo K-T, Hwang J-J, Hsieh C-S, Hsu K-L, et al. Angiotensin II activates signal transducer and activators of transcription 3 via Racl in atrial myocytes and fibroblasts: implication for the therapeutic effect of statin in atrial structural remodeling. Circulation. (2008) 117:344-55. doi: 10.1161/CIRCULATIONAHA.107.695346

142. Datta R, Bansal T, Rana S, Datta K, Datta Chaudhuri R, Chawla-Sarkar M, et al. Myocyte-derived Hsp90 modulates collagen upregulation via biphasic activation of STAT-3 in fibroblasts during cardiac hypertrophy. Mol Cell Biol. (2017) 37:e00611-16. doi: 10.1128/MCB.00611-16

143. Dai B, Cui M, Zhu M, Su W-L, Qiu M-C, Zhang H. STAT1/3 and ERK1/2 synergistically regulate cardiac fibrosis induced by high glucose. Cell Physiol Biochem Int J Exp Cell Physiol Biochem Pharmacol. (2013) 32:960-71. doi: 10.1159/000354499

144. Su S-A, Yang D, Wu Y, Xie Y, Zhu W, Cai Z, et al. EphrinB2 regulates cardiac fibrosis through modulating the interaction of
Stat3 and TGF- $\beta /$ Smad3 signaling. Circ Res. (2017) 121:617-27. doi: 10.1161/CIRCRESAHA.117.311045

145. Yuan Y, Zhang Y, Han X, Li Y, Zhao X, Sheng L, et al. Relaxin alleviates TGF $\beta 1$-induced cardiac fibrosis via inhibition of Stat3dependent autophagy. Biochem Biophys Res Commun. (2017) 493:1601-7. doi: 10.1016/j.bbrc.2017.09.110

146. Unudurthi SD, Nassal D, Greer-Short A, Patel N, Howard T, Xu X, et al. $\beta \mathrm{IV}$-spectrin regulates STAT3 targeting to tune cardiac response to pressure overload. J Clin Invest. (2018) 128:5561-72. doi: 10.1172/JCI99245

147. Hilfiker-Kleiner D, Sliwa K, Drexler H. Peripartum cardiomyopathy: recent insights in its pathophysiology. Trends Cardiovasc Med. (2008)18:173-9. doi: 10.1016/j.tcm.2008.05.002

148. Halkein J, Tabruyn SP, Ricke-Hoch M, Haghikia A, Nguyen N-Q$\mathrm{N}$, Scherr $\mathrm{M}$, et al. MicroRNA-146a is a therapeutic target and biomarker for peripartum cardiomyopathy. J Clin Invest. (2013)123:2143-54. doi: 10.1172/JCI64365

149. Ricke-Hoch M, Bultmann I, Stapel B, Condorelli G, Rinas U, Sliwa $\mathrm{K}$, et al. Opposing roles of Akt and STAT3 in the protection of the maternal heart from peripartum stress. Cardiovasc Res. (2014) 101:587-96. doi: $10.1093 / \mathrm{cvr} / \mathrm{cvu} 010$

150. Stapel B, Kohlhaas M, Ricke-Hoch M, Haghikia A, Erschow S, Knuuti J, et al. Low STAT3 expression sensitizes to toxic effects of $\beta$-adrenergic receptor stimulation in peripartum cardiomyopathy. Eur Heart J. (2017) 38:349-61. doi: 10.1093/eurheartj/ehw086

151. IDF Diabetes Atlas - Home. Available online at: http://www.diabetesatlas.org/ (accessed February 25, 2019).

152. Boudina S, Abel ED. Diabetic cardiomyopathy revisited. Circulation. (2007) 115:3213-23. doi: 10.1161/CIRCULATIONAHA.106.679597

153. Pipicz M, Demján V, Sárközy M, Csont T. Effects of cardiovascular risk factors on cardiac STAT3. Int J Mol Sci. (2018) 19:E3572. doi: 10.3390/ijms19113572

154. Jia G, Hill MA, Sowers JR. Diabetic cardiomyopathy: an update of mechanisms contributing to this clinical entity. Circ Res. (2018) 122:624-38. doi: 10.1161/CIRCRESAHA.117.311586

155. Bell DSH. Diabetic cardiomyopathy. Diabetes Care. (2003) 26:2949-51. doi: 10.2337/diacare.26.10.2949

156. Wang T, Qiao S, Lei S, Liu Y, Ng KFJ, Xu A, et al. N-acetylcysteine and allopurinol synergistically enhance cardiac adiponectin content and reduce myocardial reperfusion injury in diabetic rats. PLOS ONE. (2011) 6:e23967. doi: 10.1371/journal.pone.0023967

157. Wang C, Li H, Wang S, Mao X, Yan D, Wong SS, et al. Repeated noninvasive limb ischemic preconditioning confers cardioprotection through PKC-?/STAT3 signaling in diabetic rats. Cell Physiol Biochem Int J Exp Cell Physiol Biochem Pharmacol. (2018) 45:2107-21. doi: 10.1159/000488047

158. Xu J, Lei S, Liu Y, Gao X, Irwin MG, Xia Z, et al. Antioxidant Nacetylcysteine attenuates the reduction of Brgl protein expression in the myocardium of type 1 diabetic rats. J Diabetes Res. (2013) 2013:716219. doi: $10.1155 / 2013 / 716219$

159. Sárközy M, Szucs G, Fekete V, Pipicz M, Éder K, Gáspár R, et al. Transcriptomic alterations in the heart of non-obese type 2 diabetic Goto-Kakizaki rats. Cardiovasc Diabetol. (2016) 15:110. doi: 10.1186/s12933-016-0424-3

160. Wang Y, Li H, Huang H, Liu S, Mao X, Wang S, et al. Cardioprotection from emulsified isoflurane postconditioning is lost in rats with streptozotocin-induced diabetes due to the impairment of Brg1/Nrf2/STAT3 signalling. Clin Sci Lond Engl. (1979) 130:801-12. doi: 10.1042/CS201 50617

161. Deng F, Wang S, Zhang L, Xie X, Cai S, Li H, et al. Propofol through upregulating caveolin-3 attenuates post-hypoxic mitochondrial damage and cell death in H9C2 cardiomyocytes during hyperglycemia. Cell Physiol Biochem Int J Exp Cell Physiol Biochem Pharmacol. (2017) 44:279-92. doi: 10.1159/000484680

162. Al-Rasheed NM, Al-Rasheed NM, Hasan IH, Al-Amin MA, Al-Ajmi HN, Mahmoud AM. Sitagliptin attenuates cardiomyopathy by modulating the JAK/STAT signaling pathway in experimental diabetic rats. Drug Des Devel Ther. (2016) 10:2095. doi: 10.2147/DDDT.S109287

163. Mair M, Blaas L, Österreicher CH, Casanova E, Eferl R. JAK-STAT signaling in hepatic fibrosis. Front Biosci. (2011) 16:2794-811. doi: 10.2741/3886 
164. Sun X, Chen R, Yang Z, Sun G, Wang M, Ma X, et al. Taxifolin prevents diabetic cardiomyopathy in vivo and in vitro by inhibition of oxidative stress and cell apoptosis. Food Chem Toxicol Int J Publ Br Ind Biol Res Assoc. (2014)63:221-32. doi: 10.1016/j.fct.2013.11.013

165. Lo S-H, Hsu C-T, Niu H-S, Niu C-S, Cheng J-T, Chen Z-C. Ginsenoside Rh2 improves cardiac fibrosis via PPAR $\delta$-STAT3 signaling in type 1-like diabetic rats. Int J Mol Sci. (2017) 18:1364. doi: 10.3390/ijms18071364

166. Wang L, Li J, Li D. Losartan reduces myocardial interstitial fibrosis in diabetic cardiomyopathy rats by inhibiting JAK/STAT signaling pathway. Int J Clin Exp Pathol. (2015) 8:466-73.

167. Chang W-T, Cheng J-T, Chen Z-C. Telmisartan improves cardiac fibrosis in diabetes through peroxisome proliferator activated receptor $\delta$ (PPAR $\delta$ ): from bedside to bench. Cardiovasc Diabetol. (2016) 15:113. doi: 10.1186/s12933-016-0430-5

168. Westermann D, Rutschow S, Jager S, Linderer A, Anker S, Riad A, et al. Contributions of inflammation and cardiac matrix metalloproteinase activity to cardiac failure in diabetic cardiomyopathy: the role of angiotensin type 1 receptor antagonism. Diabetes. (2007) 56:641-6. doi: 10.2337/db06-1163

169. Wang L, Yuan T, Du G, Zhao Q, Ma L, Zhu J. The impact of 1,25-dihydroxyvitamin D3 on the expression of connective tissue growth factor and transforming growth factor- $\beta 1$ in the myocardium of rats with diabetes. Diabetes Res Clin Pract. (2014)104:226-33. doi: 10.1016/j.diabres.2014.01.031

170. Lo S-H, Hsu C-T, Niu H-S, Niu C-S, Cheng J-T, Chen Z-C. Cryptotanshinone inhibits STAT3 signaling to alleviate cardiac fibrosis in type 1-like diabetic rats. Phytother Res. (2017) 31:638-46. doi: 10.1002/ptr.5777

171. Li H, Yao W, Liu Z, Xu A, Huang Y, Ma X-L, et al. Hyperglycemia abrogates ischemic postconditioning cardioprotection by impairing AdipoR1/Caveolin-3/STAT3 signaling in diabetic rats. Diabetes. (2016) 65:942-55. doi: $10.2337 / \mathrm{db} 15-0782$

172. Gross ER, Hsu AK, Gross GJ. Diabetes abolishes morphine-induced cardioprotection via multiple pathways upstream of glycogen synthase kinase-3ß. Diabetes. (2007) 56:127-36. doi: 10.2337/db06-0907

173. Lin J, Wang T, Li Y, Wang M, Li H, Irwin MG, et al. N-acetylcysteine restores sevoflurane postconditioning cardioprotection against myocardial ischemiareperfusion injury in diabetic rats. J Diabetes Res. (2016) 2016:9213034. doi: 10.1155/2016/9213034

174. Liu J, Wang H, Li J. Inflammation and inflammatory cells in myocardial infarction and reperfusion injury: a double-edged sword. Clin Med Insights Cardiol. (2016) 10:79-84. doi: 10.4137/CMC.S33164

175. Halade GV. Targeting resolution of inflammation following myocardial infarction. J Cardiol Clin Res. (2013) 1:1008.

176. Fielding CA, McLoughlin RM, McLeod L, Colmont CS, Najdovska M, Grail D, et al. IL-6 regulates neutrophil trafficking during acute inflammation via STAT3. J Immunol. (2008) 181:2189-95. doi: 10.4049/jimmunol.181.3.2189

177. Lee T-M, Harn H-J, Chiou T-W, Chuang M-H, Chen C-H, Chuang $\mathrm{C}-\mathrm{H}$, et al. Preconditioned adipose-derived stem cells ameliorate cardiac fibrosis by regulating macrophage polarization in infarcted rat hearts through the PI3K/STAT3 pathway. Lab Invest. (2019) 99:634-47. doi: 10.1038/s41374-018-0181-x

178. Ma Y, Mouton AJ, Lindsey ML. Cardiac macrophage biology in the steadystate heart, the aging heart, and following myocardial infarction. Transl Res J Lab Clin Med. (2018) 191:15-28. doi: 10.1016/j.trsl.2017.10.001

179. Carow B, Rottenberg ME. SOCS3, a major regulator of infection and inflammation. Front Immunol. (2014) 5:58. doi: 10.3389/fimmu.2014.00058
180. Hilfiker-Kleiner D, Shukla P, Klein G, Schaefer A, Stapel B, Hoch M, et al. Continuous glycoprotein-130-mediated signal transducer and activator of transcription-3 activation promotes inflammation, left ventricular rupture, and adverse outcome in subacute myocardial infarction. Circulation. (2010) 122:145-55. doi: 10.1161/CIRCULATIONAHA.109.933127

181. Zgheib C, Zouein FA, Kurdi M, Booz GW. Differential STAT3 signaling in the heart. JAK-STAT. (2012) 1:101-10. doi: 10.4161/jkst.19776

182. Murray PJ. STAT3-mediated anti-inflammatory signalling. Biochem Soc Trans. (2006) 34:1028-31. doi: 10.1042/BST0341028

183. Hutchins AP, Diez D, Miranda-Saavedra D. The IL-10/STAT3-mediated antiinflammatory response: recent developments and future challenges. Brief Funct Genomics. (2013)12:489-98. doi: 10.1093/bfgp/elt028

184. Lörchner H, Pöling J, Gajawada P, Hou Y, Polyakova V, Kostin $S$, et al. Myocardial healing requires Reg3 $\beta$-dependent accumulation of macrophages in the ischemic heart. Nat Med. (2015)21:353-62. doi: $10.1038 / \mathrm{nm} .3816$

185. Shirakawa K, Endo J, Kataoka M, Katsumata Y, Yoshida N, Yamamoto $\mathrm{T}$, et al. IL (interleukin)-10-STAT3-galectin-3 axis is essential for osteopontin-producing reparative macrophage polarization after myocardial infarction. Circulation. (2018) 138:2021-35. doi: 10.1161/CIRCULATIONAHA.118.035047

186. Lee T-M, Chang N-C, Lin S-Z. Dapagliflozin, a selective SGLT2 Inhibitor, attenuated cardiac fibrosis by regulating the macrophage polarization via STAT3 signaling in infarcted rat hearts. Free Radic Biol Med. (2017)104:298 310. doi: 10.1016/j.freeradbiomed.2017.01.035

187. Rong J, Li L, Jing L, Fang H, Peng S. JAK2/STAT3 pathway mediates protection of metallothionein against doxorubicin-induced cytotoxicity in mouse cardiomyocytes. Int J Toxicol. (2016) 35:317-26. doi: $10.1177 / 1091581815614261$

188. Keeney JTR, Ren X, Warrier G, Noel T, Powell DK, Brelsfoard $\mathrm{JM}$, et al. Doxorubicin-induced elevated oxidative stress and neurochemical alterations in brain and cognitive decline: protection by MESNA and insights into mechanisms of chemotherapy-induced cognitive impairment (“chemobrain”). Oncotarget. (2018) 9:30324-39. doi: 10.18632/oncotarget.25718

189. Gu C, Li T, Jiang S, Yang Z, Lv J, Yi W, et al. AMP-activated protein kinase sparks the fire of cardioprotection against myocardial ischemia and cardiac ageing. Ageing Res Rev. (2018)47:168-75. doi: 10.1016/j.arr.2018. 08.002

190. Yu L-M, Di W-C, Dong X, Li Z, Zhang Y, Xue X-D, et al. Melatonin protects diabetic heart against ischemia-reperfusion injury, role of membrane receptor-dependent cGMP-PKG activation. Biochim Biophys Acta Mol Basis Dis. (2018)1864:563-78. doi: 10.1016/j.bbadis.2017.11.023

Conflict of Interest: The authors declare that the research was conducted in the absence of any commercial or financial relationships that could be construed as a potential conflict of interest.

Copyright (c) 2019 Harhous, Booz, Ovize, Bidaux and Kurdi. This is an open-access article distributed under the terms of the Creative Commons Attribution License (CC $B Y)$. The use, distribution or reproduction in other forums is permitted, provided the original author(s) and the copyright owner(s) are credited and that the original publication in this journal is cited, in accordance with accepted academic practice. No use, distribution or reproduction is permitted which does not comply with these terms. 